\title{
2 A review and scientometric analysis of global 3 Building Information Modelling (BIM) research in 4 the Architecture, Engineering and Construction 5 (AEC) industry
}

Ziwen Liu ${ }^{1,2,}$, ,Yujie Lu ${ }^{3,4}$ Lu Chang Peh ${ }^{1}$

1 School of Science \& Technology, Singapore University of Social Science, 463 Clementi Rd, Singapore 599494; Zwliu001@suss.edu.sg; Lukepehlc@suss.edu.sg

2 Digitalisation Department, Built Environment Research and Innovation Institute (BERII), Building and Construction Authority, Singapore 579700; Liu_ziwen@bca.gov.sg

3 Department of Building Engineering, College of Civil Engineering, Tongji University, China 200092

\author{
4 Key Laboratory of Performance Evolution and Control for Engineering Structures of Ministry of \\ Education, Tongji University, China 200092; Lu6@tongji.edu.cn \\ * Correspondence: Zwliu001@suss.edu.sg; Tel.: +65-67304527
}

Abstract: In the recent decade, Building Information Modelling (BIM) has widely been adopted in the Architecture, Engineering and Construction (AEC) industry and completely upended the way we build. While BIM continues gain momentum in the industry, it has also attracted increasing attentions from researchers. However, most of the current study focuses on reviewing BIM for management, BIM for green building, BIM for infrastructure and BIM for Facilities Management (FM). There are few studies about Global BIM review and to discuss their complex interconnections. In this study, we adopted a scientometric analysis method to review global BIM research from 2004-2019. A total of 1455 scholarly bibliographic records obtained from Web of Science Core Collection databased were established for the analysis. This study has identified the top productive and influential researchers, research institutes, regions/countries, subject categories and journals in the BIM field. In addition, 11 clusters of Global BIM research were also identified including construction project, green BIM, construction safety planning, automated IFC-based workflow and so on. Authors distinguished 11 clusters of global BIM research into 3 stages, namely formulating stage, accelerating stage and transforming stage. Furthermore, authors reviewed the BIM policy of Singapore and observed there is a co-production relationship between evolution of BIM policy and global BIM research. These findings provide valuable information for researchers, practitioners and policy makers by visualizing the current progress in the research field of BIM and highlighting future research needs.

Keywords: Building information modelling; Co-citation network; Literature Review; Research visualization; Scientometrics.

\section{Introduction}

The Architecture, Engineering and Construction (AEC) industry are undergoing a significant shift from traditional labour-intensive methods to automation through the use of information technology, Building Information Modelling (BIM) has played a crucial role in this transformation[1, 2]. The United States National Institute of Building Sciences (NIBS) gives the most authoritative 
definition: "A BIM is a digital representation of physical and functional characteristics of a facility. As such it serves as a shared knowledge resource for information about a facility forming a reliable basis for decisions during its lifecycle from inception onward [3] ."

Literature review refers to a kind of academic paper which is written by making a comprehensive analysis for a large amount of collected information data on a certain topic. As a type of scientific literature, literature review is considered a stopgap for in-depth understanding of the research fields [4]. Through the systemizing of existing researches, the fronts and trends of current researches can be found, so as to provide strong support and argumentation for the establishment of new research topics in the future.

Most of previous researches focused on the research literature review of BIM and other fields, such as managerial areas of BIM [4], BIM for Green Buildings[5], BIM for infrastructure[6], BIM for Facilities Management [7]. To illustrate, Qinghua He et al. [4] reviewed 126 articles on managerial areas of BIM (BIM-MA) published from 2007 to 2015 and proposed an integrated conceptual framework to summarize current status and structure future direction of MA-BIM.Y Lu et al. [5] conducted a comprehensive understanding and critical reflection on the relationship between BIM and Green Building and explained it systematically using the classification of "Green BIM Triangle" taxonomy through an in-depth review of hundreds of journal articles published from 1999 to 2016 and 12 kinds of BIM software widely used in AEC industry. Alex Braddly et. al [6] presented a review of 250 key publications in the area of BIM for infrastructure and analyses the trends for BIM development for infrastructure according to publication year, publication origin, project phase in question and publication scope. Mustafa Hilal et.al [7] adopted scientometric approach using science mapping techniques to examine BIM-FM articles using Web of Science (WOS) database for the period between 2000 and April, 2018.

Seems there are only few studies about region and global BIM review, for instance, Saka and Chan[8] presented a scientometric review and metasynthesis of BIM development in the African AEC industry, findings revealed a varying level of BIM growth, with North Africa, West Africa, and Southern Africa leading the research development, whilst East Africa and Central Africa are slightly lagging behind. In addition, the authors identified the major challenges encountered in BIM adoption are people/process-related barriers. X Zhao[9] conducted a scientometric review of scientific literature relating to BIM in 2005-2016, and identified hot 10 topics of BIM research were: mobile and cloud computing, laser scan, augmented reality, ontology, safety rule and code checking, semantic web technology, and automated generation. Although, the previous studies such as Saka and Chan[8] and X Zhao[9] analyzed 93 and 614 bibliographic records respectively as compared to relatively higher corpus of papers in this study (1455 articles). Moreover, compared with X Zhao[9]'s 12 review span, this review span is 16 years. Also, no previous review focus on venation of BIM development, this study distinguished 11 clusters of global BIM research into 3 stages, namely formulating stage, accelerating stage and transforming stage. In addition, authors reviewed the BIM policy of Singapore and observed there is a co-production relationship between evolution of BIM policy and global BIM research.

This research adopts a quantitative and qualitative analysis method to analyze 1455 journal articles related to BIM published from 2004-2019. In the quantitative analysis, distribution of BIMs publication was analyzed by with times, authors, countries, research institute, subject categories and published journal. In the qualitative analysis, 1455 bibliometric record was imported into scientometric toolkit for visualization analysis, co-authorship network, network of countries/regions 
89

90

91

92

and institutions, network of co-occurring subject categories, network of co-occurring keywords, journal co-citation network, author co-citation network and document co-citation network. In addition, co-citation clusters were identified and conducted critical review for the top three documents in each cluster.

\section{Research Method}

The research framework includes defining literature database and search rules, conducting preliminary retrieval, data processing and analysis, as illustrated in Figure. 1. The paper selection process in this study was referred to the methods used in other review articles, such as $[6,8,13]$.

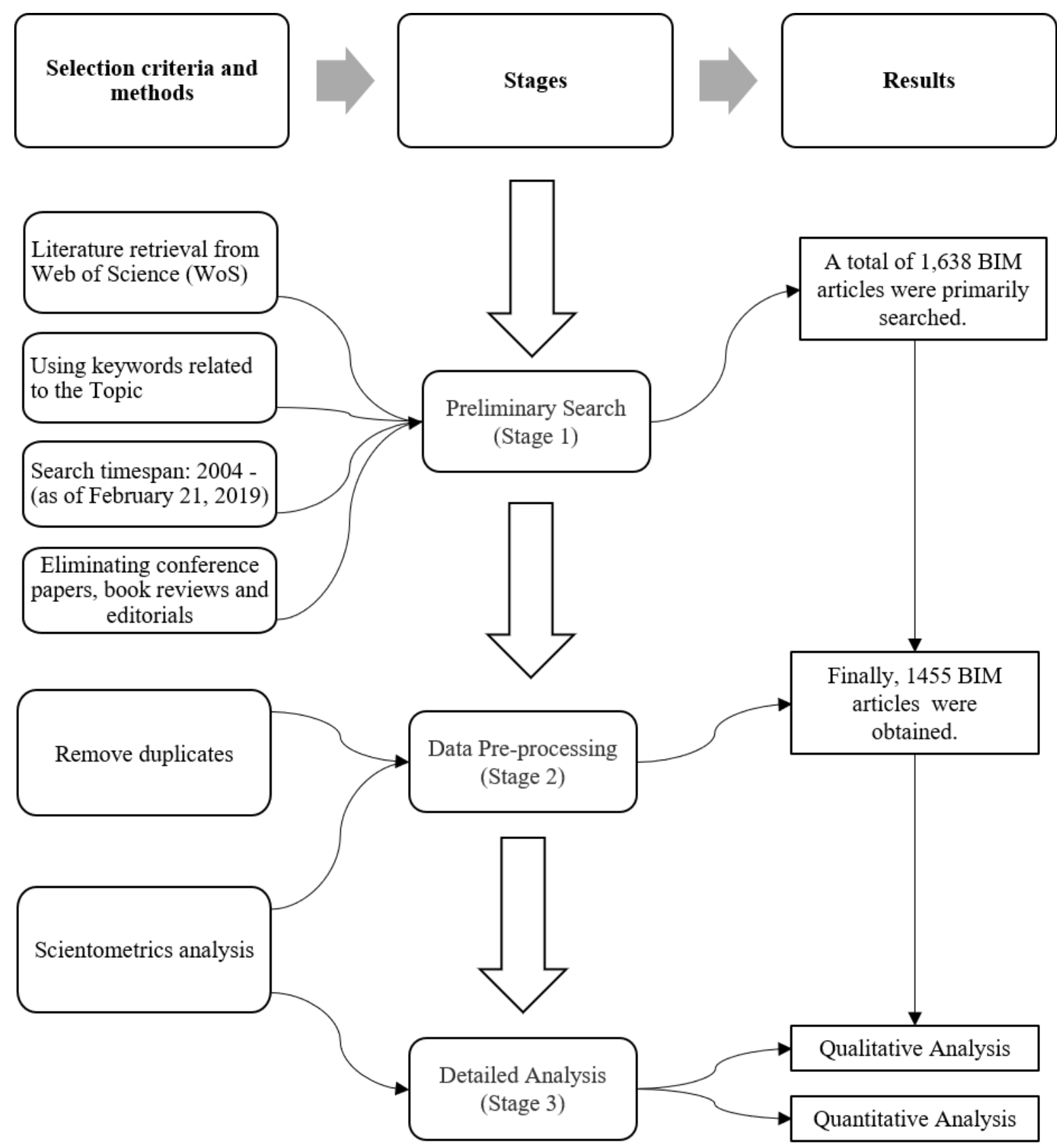

Figure 1. Research Framework

\subsection{Preliminary Search}

The research boundary have been defined by following the rules below. Firstly, the research data is obtained from Web of Science (WoS) Core Collection. For scientific text data, all literature

102 information except the main body is included in the index database. The WoS, an authoritative 
103

104

105

106

107

108

109

110

111

112

113

114

115

116

117

118

\section{9}

120

121

122

123

124

125

database in the research field, is selected for literature search. The data structure of WoS is relatively complete, including literature types, authors, journals, keywords, abstracts, institutes and references. Engineering, architecture and information construction are also fully included in the database which also contains major journals and conference papers. More than 18,000 influencing journals around the world are covered by WoS, including open journals and more than 180,000 pieces of conference proceedings, and over 80,000 books from around the world[10]. Information obtained from WoS is considered sufficient for this study.

Secondly, the initial search takes the topics as follows: "Building information modelling", "Building information modeling" or "Building information model", "' representing precise phrase search. Taking into account articles comprehensively covering BIM and the avoidance of target literature omission, the time span was set from 2004 to 2019. The first journal article [11] on BIM was published in 2004, so the year 2004 was set as an the initial year. The retrieval was conducted on February 21, 2019. In January 2004, John Haymaker et al. [11] firstly proposed "building information modeling" in keywords of a paper and formalized a reusable reasoning module called "Perspectors" which can automatically construct a task-specific engineering view known as "Perspectives" by engineers. The method has been verified by a real project.

Thirdly, only English articles and reviews are selected. To ensure the comprehensiveness and reliability of the results of literature review, the literature referred to is limited to journals, excluding book reviews, letters, news reports and conference abstracts. This is because journal papers usually provide more comprehensive and higher-quality information than other types of publications. A total of 3,033 articles on BIM were retrieved for the first time, with the database interface shown in Figure. 2.

126

127

128

129

130

131

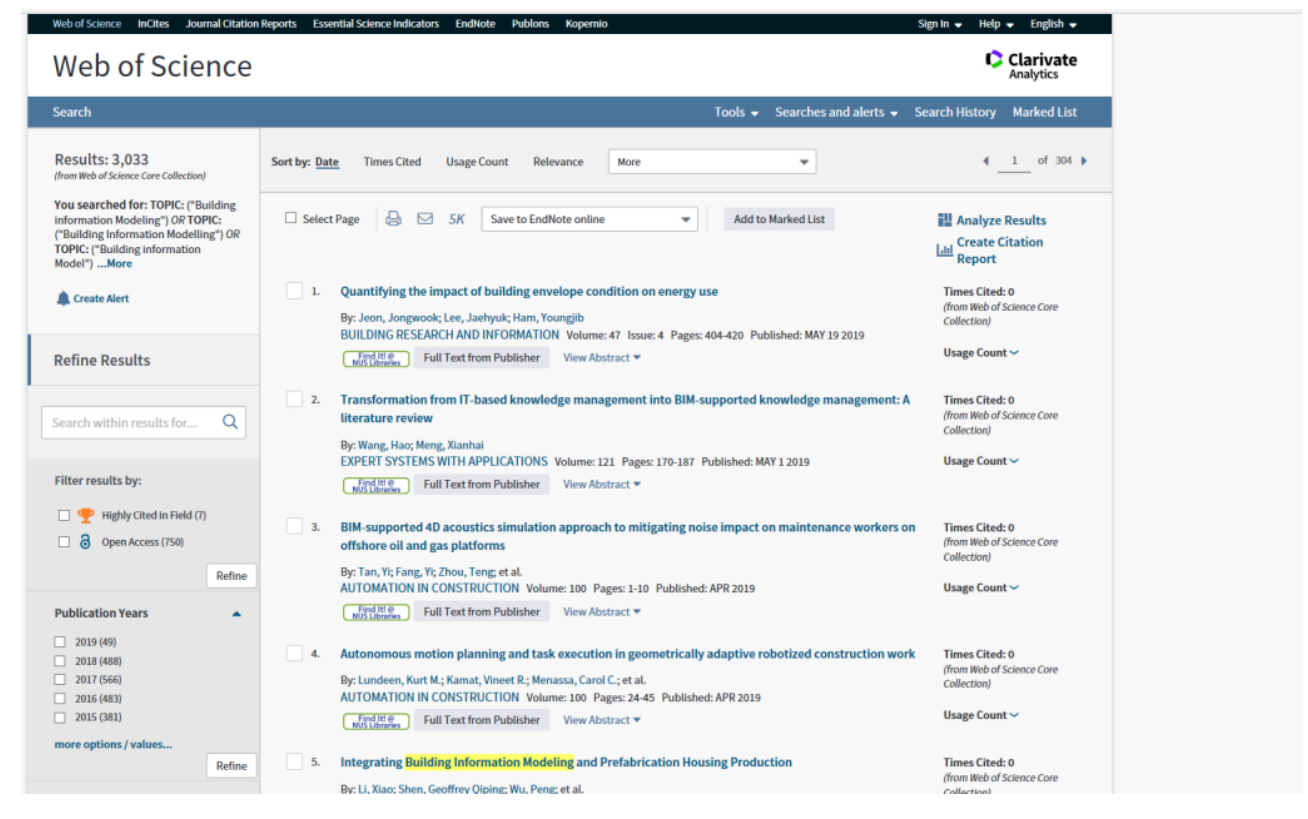

Figure 2. Article retrieved

Through refining and duplicate checking, 1,455 articles on BIM were obtained. The specific data collection process is shown in Table 1.

Table 1. Articles retrieved at different stages 
Topics: "Building information modelling"

Or "Building information modeling"

Or "Building information model"

3033

Database: Web of Science Core Collection

Web of Science

Timespan: 2004 to 21Feb 2019

Languages: English

Exclude conference articles

Document Types: Article + Review

Remove duplicates

\subsection{Data pre-processing}

Before performing detailed analysis, data filtering and duplicate removal for WoS format of data should be carried out. It can help to remove redundant data and could be used for removing news with same content by selecting the file with content of journalism[12]. As shown in Figure.3, a total of 1,455 valid BIM articles were obtained after data pre-processing.

\subsection{Research toolkits}

Common scientometrics toolkits are CiteSpace[13], Science of Science (Sci2) Tool[14], BibExcel[15]. These toolkits can help scholars to quickly and effectively perform visualized information analysis. CiteSpace was developed at Drexel University (USA) and can be freely downloaded. It is mainly used to detect, analyze, and visualize patterns and trends in scientific literature[16]. Its primary goal is to facilitate the analysis of emerging trends in knowledge domain. Featuring perfect functions, CiteSpace is characterized by spectral clustering and citation burst[16]. It focuses finding critical points in the development of a field or a domain, especially intellectual turning points and pivotal points [17].In the whole process of constructing knowledge maps, the processing of each step by CiteSpace is reasonable, with the highlight of core items. Therefore, CiteSpace is used to analyze literature in this study.

\subsection{Parameters setting}

The time span settings were from 2004 to 2019 for BIM bibliographic records. Each year was selected as a time slice and 16-time segments were obtained. The Cosine algorithm was selected for the correlation strength of network nodes. The threshold of time slice was set to 50, that is to say, the first 50 (Top 50) were extracted. Finally, redundant links was removed by Pathfinder in network pruning, which was recommended by Chen and Morris[18]. Moreover, the corresponding node types were selected, and the corresponding scientific knowledge map was drawn according to the research needs. 
162

163

164

165

166

167

168

169

170

171

172

173

174

175

176

177

178

179

180

181

182

183

184

185

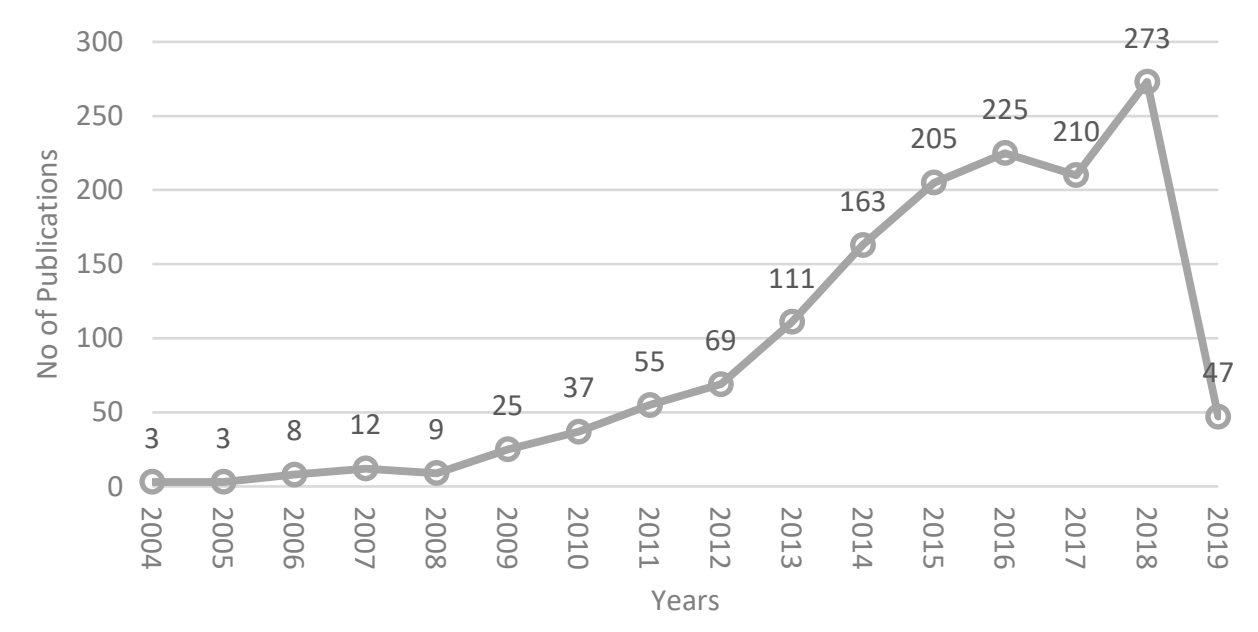

186

188

189

190

191

192

193

194

195

This section aims to conduct a quantitative analysis for 1455 BIM bibliometrics record. The development status of BIM research field can be reflected by the diachronic change trend of the amount of publications in this field. In order to understand the research achievements of BIM in the last decade, statistics of distribution of BIMs publication were analyzed by their publishing times, authors, countries, research institute, subject categories and published journal.

\subsection{Distribution of BIM publications with times}

A total of 1,455 BIM publications collected from the WoS database are shown in Figure. 3, temporal distribution of which is recorded. It can be found that the volume of research documents related to BIM has been on a rise since 2008, with a sharp increase especially since 2012. BIM is receiving extensive attention and ushering in the upsurge of development in the world. As shown in Figure.3, published articles in the BIM field have been greatly increased since 2008. A total of 708 BIM papers were published in the last three years (from 2016 to 2018), accounting for approximately half of the literature in this study.

Seen from Figure. 3, the development of BIM research has continued since the beginning of the 20th century. In January 2004, John Haymaker et al. [11] firstly proposed "building information modeling" in keywords of a paper. In 2005, Kenny TC et al. [19] tried to explore other dimensions of BIM. Low frequency of BIM usage was mentioned in the paper. Traditional entity-based CAD software was still taken as the actual drawing tool. Core obstacles include the difference between architecture design and drafting, inadequate objects and object customization capability, the complex and timeconsuming modeling process, lack of training and technical support, lack of customer requirements, additional file acquisition costs and incapability of obtaining free trials software. In addition, the separation of design and drafting has become a common practice, which may be the most prominent obstacle to the widespread use of BIM and the $\mathrm{nD}$ modeling in the future.

Figure.3: Distribution of BIM publications with times

\subsection{Distribution of published papers with authors}

According to literature retrieved from WoS, the top 10 most productive BIM authors were identified, as shown in Table 2. Xianyu Wang from Curtin University, Australia, tied for the first place with 41 BIM publications, followed by Rafael Sacks from Israel Polytechnic University and Jack C. P. Cheng. Among the top 10 productive authors, three come from Curtin University of Australia, two from Hong Kong Universities, and another two from the University of Seoul and Yonsei University, South Korea. 
196

197

Table 2. Top 10 productive BIM article authors

\begin{tabular}{lllllll}
\hline SN & Rank & Author & Country & Institution & Count & \% of 1455 \\
\hline 1 & 1 & Xiangyu Wang & Australia & Curtin University & 41 & 2.82 \\
2 & 2 & Rafael Sacks & Israel & $\begin{array}{l}\text { Technion-Israel Institute } \\
\text { of Technology }\end{array}$ & 30 & 2.06 \\
3 & 3 & Jack C.P. Cheng & Hong Kong & $\begin{array}{l}\text { Hong Kong University of } \\
\text { Science and Technology }\end{array}$ & 24 & 1.65 \\
4 & 4 & Raja R.A. Issa & USA & University of Florida & 19 & 1.31 \\
5 & 4 & Heng Li & Hong Kong & $\begin{array}{l}\text { Hong Kong Polytechnic } \\
\text { University }\end{array}$ & 19 & 1.31 \\
6 & 5 & Charles M. & USA & $\begin{array}{l}\text { Georgia Institute of } \\
\text { Technology }\end{array}$ & 18 & 1.24 \\
7 & 5 & Kim Hyunjoo & South Korea & University of Seoul & 18 & 1.24 \\
8 & 5 & Ghang Lee & South Korea & Yonsei University & 18 & 1.24 \\
9 & 5 & Jun Wang & Australia & Curtin University & 18 & 1.24 \\
10 & 6 & Heap-Yih Chong & Australia & Curtin University & 17 & 1.17 \\
\hline
\end{tabular}

198

Seen from the number of publications in countries where the top ten authors are located, the top three countries are Australia (76 publications), Hong Kong (43 publications) and South Korea (36

201 publications). It is also worth mentioning that the volume of publications by top 10 productive

202 authors accounts for approximately $15 \%$ of the total.

203 3.3. Distribution of published literature with countries/regions

204 The information of countries/regions in articles can be obtained from the published

205 bibliographic records, so as to determine the main countries/regions of the publications. According

206 to the records in WoS, a total of 1,455 BIM articles were published in 75 countries/regions. Top 10

207 productive countries/regions are shown in Table 3.

Table 3. Top 10 productive BIM articles countries/regions

\begin{tabular}{llll}
\hline SN & Country/Region & Count & \% of 1455 \\
\hline 1 & USA & 341 & 23.44 \\
2 & China & 224 & 15.40 \\
3 & England & 194 & 13.33 \\
4 & Australia & 152 & 10.45 \\
5 & South Korea & 151 & 10.38 \\
6 & Germany & 70 & 4.81 \\
\hline
\end{tabular}




\begin{tabular}{llll}
\hline 7 & Canada & 60 & 4.12 \\
8 & Taiwan & 55 & 3.78 \\
9 & Italy & 41 & 2.82 \\
10 & Malaysia & 36 & 2.47 \\
11 & Netherlands & 36 & 2.47
\end{tabular}

With regard to the contribution of the total volume of BIM documents, publications in the top 10 countries accounted for approximately $93 \%$ of the total volume of BIM documents. The top three countries, namely, the United States, China and the United Kingdom contributed 341, 224 and 194 papers respectively, accounting for more than half of the total volume. In four Asian countries/regions among the top 10, including China, South Korea, Taiwan and Malaysia, they accounted for approximately 30 percent of the total publications. In European countries, there were 194 publications in England, 70 publications in Germany and 41 publications in Italy, accounting for about 20 percent of the total publications. In North American countries, 341 were published in the United States and 60 were in Canada, taking up approximately 27 percent of the total publications. In Oceania, Australia contributed more than 10 percent of the total.

\section{4. distribution of published documents with research institutes}

Information of research institutes in publications can be obtained from bibliographic records as well, so as to determine the main research institutes of the publications. According to records in WoS, a total of 1,128 research institutes have published 1,455 BIM articles. The top 10 productive institutes are shown in Table 4.

Table 4. Top 10 productive research institutes

\begin{tabular}{|c|c|c|c|c|c|}
\hline SN & Rank & Research Institute & Country/Region & Record & $\begin{array}{ll}\% & \text { of } \\
1455 & \end{array}$ \\
\hline 1 & 1 & Curtin University & Australia & 69 & 4.74 \\
\hline 2 & 2 & Georgia Institute Technology & USA & 58 & 3.99 \\
\hline 3 & 3 & $\begin{array}{l}\text { Hong Kong Polytechnic } \\
\text { University }\end{array}$ & Hong Kong & 42 & 2.89 \\
\hline 4 & 4 & Kyung Hee University & South Korea & 40 & 2.75 \\
\hline 5 & 5 & Tsinghua University & China & 29 & 1.99 \\
\hline 6 & 5 & University of Hong Kong & Hong Kong & 29 & 1.99 \\
\hline 7 & 6 & Pennsylvania State University & USA & 28 & 1.92 \\
\hline 8 & 7 & Yonsei University & South Korea & 27 & 1.86 \\
\hline 9 & 8 & $\begin{array}{l}\text { Hong Kong University of Science } \\
\text { Technology }\end{array}$ & Hong Kong & 26 & 1.79 \\
\hline 10 & 8 & $\begin{array}{l}\text { Technion - Israel Institute of } \\
\text { Technology }\end{array}$ & Israel & 26 & 1.79 \\
\hline 11 & 8 & University of Florida & USA & 26 & 1.79 \\
\hline 12 & 8 & University of Salford & UK & 26 & 1.79 \\
\hline
\end{tabular}


In terms of the contribution of the total volume of BIM literature, the top 10 research institutes accounted for nearly 30 percent of the total volume of published BIM documents. The top three research institutes were Curtin University, Georgia Institute Technology and Hong Kong Polytechnic University Regionally, there were 3 Hong Kong research institutes among the top 10 The total contribution of Hong Kong was 97 , accounting for $23 \%$ and $7 \%$ of the top 10 literature volume and the total volume, respectively. There were also 3 USA research institutes, Georgia Institute Technology, Pennsylvania State University and University of Florida. In addition, among the top 10 research institutes, Asian research institutes contributed 193 publications, taking up $45 \%$ and $13 \%$ of the top 10 literature volume and the total volume, respectively.

\section{5. distribution of published documents with subject categories}

A total of 1,544 BIM bibliographic records loaded from WoS were allocated to 86 WoS categories. The top 10 productive research institutes are shown in Figure.5. The top 3 categories were Engineering Civil with 813 publications, Construction Building Technology and Engineering Industry with 582 and 156 publications, respectively. Each of them accounted for $56 \%, 40 \%$ and $11 \%$ of the total volume of publications.

Table 5. Top 10 productive WoS subject categories

\begin{tabular}{llll}
\hline SN & Web of Science Categories & Record & $\begin{array}{l}\text { \% } \\
\mathbf{1 4 5 5}\end{array}$ \\
\hline 1 & Engineering Civil & 813 & 55.88 \\
2 & Construction Building Technology & 582 & 40.00 \\
3 & Engineering Industrial & 156 & 10.72 \\
4 & Engineering Multidisciplinary & 155 & 10.65 \\
5 & Management & 125 & 8.59 \\
6 & Computer Science Interdisciplinary Applications & 109 & 7.49 \\
7 & Architecture & 86 & 5.91 \\
8 & Computer Science Artificial Intelligence & 71 & 4.88 \\
9 & Green Sustainable Science Technology & 64 & 4.40 \\
10 & Environmental Sciences & 60 & 4.12 \\
\hline
\end{tabular}

According to statistical data obtained from WoS core collection database, the top 10 Journals of BIM research were determined. BIM literature publications are shown in Table.6. There were 294 papers published on Automation in Construction, occupying the first place in BIM research, followed by the Journal of Information Technology in construction with 96 papers and the Journal of Computing in Civil Engineering with 64 papers. Among these 10 journals, 4 were published in the USA and 3 were published in the UK. 


\begin{tabular}{llllc}
\hline SN & Source Title & $\begin{array}{l}\text { Host } \\
\text { country }\end{array}$ & Count & $\begin{array}{l}\text { \% of } \\
\mathbf{1 4 5 5}\end{array}$ \\
\hline 1 & Automation in construction & Netherlands & 294 & 20.21 \\
2 & Journal of information technology in construction & Sweden & 96 & 6.60 \\
3 & Journal of computing in civil engineering & USA & 64 & 4.40 \\
4 & Journal of construction engineering and management & USA & 61 & 4.19 \\
5 & Advanced engineering informatics & UK & 54 & 3.71 \\
6 & Journal of management in engineering & USA & 34 & 2.34 \\
7 & Architectural engineering and design management & UK & 30 & 2.06 \\
8 & Engineering construction and architectural management & UK & 29 & 1.99 \\
9 & Journal of civil engineering and management & Lithuania & 25 & 1.72 \\
10 & Buildings & USA & 24 & 1.65 \\
\hline
\end{tabular}

\section{The results of scientometric analysis}

\subsection{Co-author analysis}

The information of the authors, research institutions and countries/regions can be obtained from bibliographic records, so as to determine the leading researchers, institutions, and countries/regions of BIM research [20]. Therefore, a co-authorship network, as well as a network of co-authors' institutions and countries/regions, was generated.

\subsubsection{Co-authorship network}

The co-authorship network is shown in Figure.4. Each node represents an author, and links between the authors represent the collaboration established through co-authors in the article. The node size represents the number of publications, and the thickness of the links represents the level of the partnership in a specified year. Colors of the links such as blue, green, yellow, orange and red correspond to different years from 2004 to 2019. The bibliographic records of 1,455 BIM documents were analyzed with CiteSpace. There were 312 nodes and 336 links for the co-authorship network.

As shown in Figure.4, there are multiple closed-loop circuits in the research of collaboration, indicating that researchers in these closed-loop circuits have established strong collaboration. For example, the closed-loop circuit of Rafael Sacks, Yeon-Suk Jeong and Charles M. Eastman implied strong cooperation by these authors in 2008 and 2009. Jochen Teizer and Markus König established strong cooperation in 2019. In addition, several research communities, including multiple authors and one or two productive authors, were identified after the co-authorship network analysis. For example, Xiangyu Wang and Jun Wang are two core authors of a research group which also includes Martijn Truijens, Yi Jiao and Shih-Chung Kang. Inhan Kim is the main author of a research group composed of Shen zhenghua, Jungho Yu etc. There is also a research community in recent years, such as Liang Ma, Poorang Piroozfar and Ruoyu Jin. 


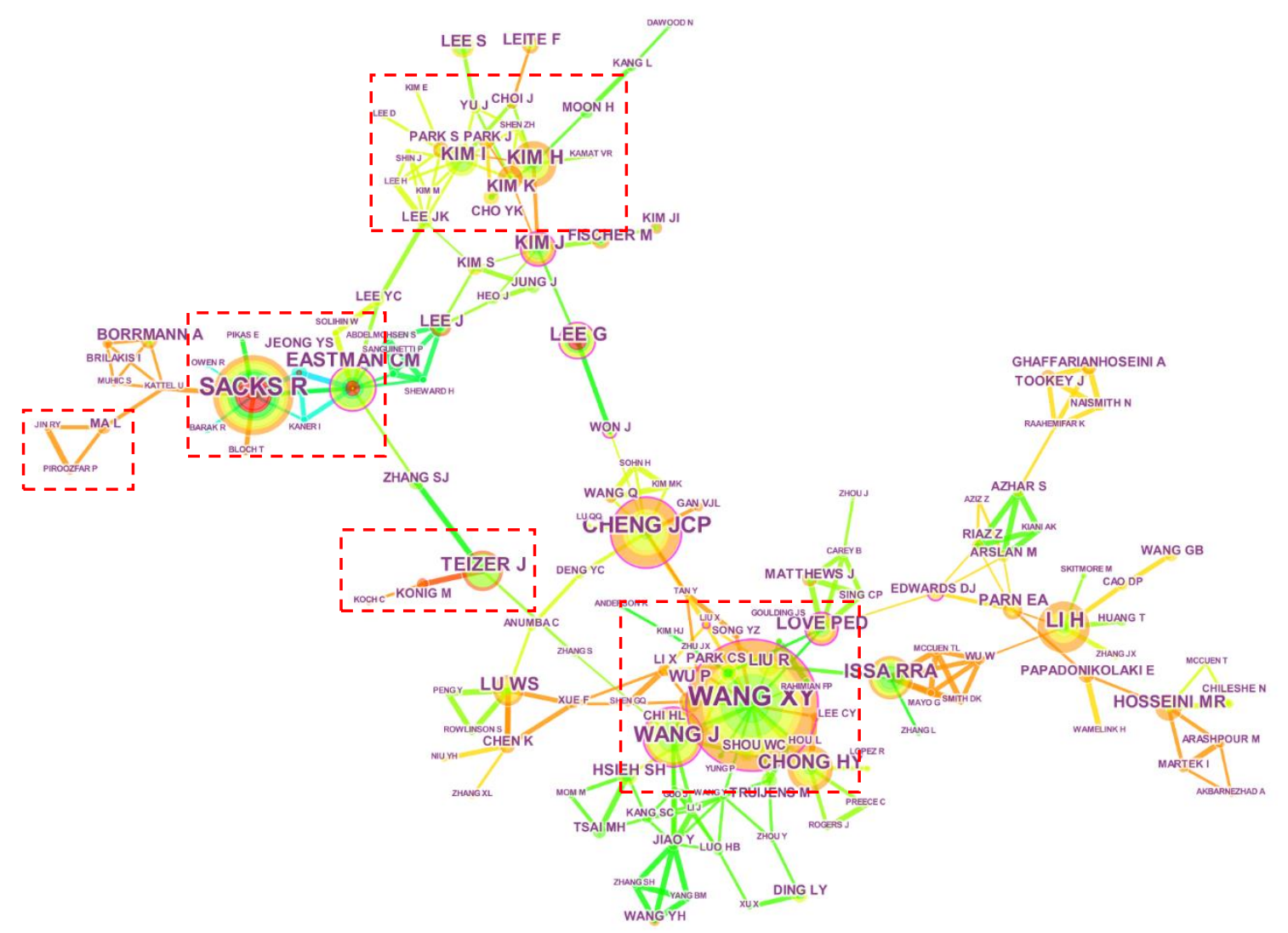

Figure.4: Distribution of BIM publications with times

The following two important indicators are usually used to measure the importance of authors, articles, research institutes and countries/regions:

- Betweenness centrality (noted with purple rings)

In the graph theory, the centrality of nodes is the theoretical property of a graph, which quantifies the position importance of nodes in the network. A commonly used centrality measure is betweenness centrality which is an index measuring the importance of nodes in the network. It is defined as the ratio of the shortest path between two nodes to the sum of all these shortest paths. Nodes with high betweenness centrality usually connect two or more large groups of nodes to each node. This index is used to discover and measure the importance of literature in CiteSpace, and a purple highlighted ring is used to highlight this kind of literature (or authors, periodicals and research institutes, etc.). Clusters in the network can be easily separated and influencing and revolutionary scientific publications can be identified by these nodes. In Figure.6, purple rings are used for nodes of Xiangyu Wang (centrality $=0.18$ ), Jack C.P. Cheng (centrality $=0.13$ ), Jun Wang (centrality $=0.12$ ), Peter Love (centrality $=0.12$ ) and other several authors, and they connect different groups of authors.

\section{- Citation burst detection (noted in red)}

Citation burst detection is an important index for studying the most active field. One of CiteSpace's breakthroughs is to provide a burst item analysis method based on the word frequency growth algorithm, which detects rapidly growing specialized words in a short period of time by counting citation keywords. The characteristics of temporal distribution and dynamic variability of the burst items can better reflect the research fronts and development trend in the knowledge domain. Citation burst detection is used for emergencies, which can last for a year or several years. Citation burst detection can be used as an evidence to show that a particular publication is heavily cited at a 
303

304

305

306

307

308

certain time. In other words, the publication has attracted great attention from the scientific community in that period of time. Burst detection in CiteSpace is based on Kleinberg algorithm. As shown in Figure 2.9, the four authors received citation bursts of different intensities by red notes. According to the burst strength, the rank was Sacks R (strength $=6.09,2009-2013$ ), Eastman CM (strength $=3.82$, 2009-2012), Jeong YS (strength $=3.32$, 2009-2010) and Lee G (strength $=3.13$, 20122014)

\subsubsection{Network of countries/regions}

In order to understand the research status in the field of BIM in the world, a network of countries/regions was generated. There are 51 nodes and 113 links in the network. In Figure.5, the size of nodes represents the appearance frequency of the country in which the author is located in. The larger the circle is, the higher appearance frequency of authors in the country is. The color of the rings represents the authors' literature publication time in the corresponding country, and the wider the single ring is, the higher appearance frequency of authors in the country is within a certain time period.

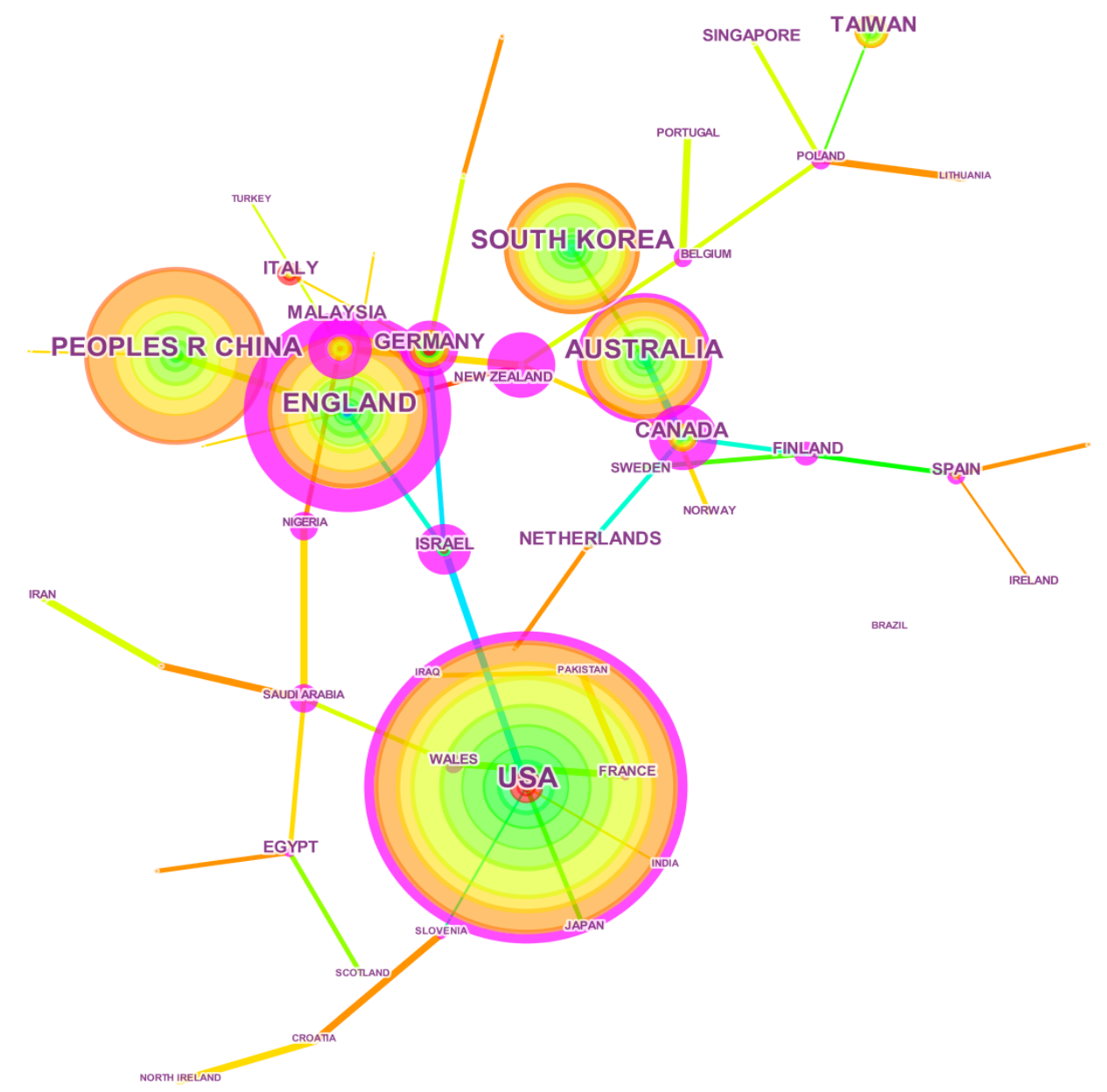

Figure.5: Network of countries/regions

As shown clearly in Figure.5, the circle area of the USA is the largest in the field of BIM research with absolute advantages. It shows that the United States has strong research strength and influence in the field of BIM. China ranks the second, suggesting the moderate BIM research power of the country. The United Kingdom ranks the third, South Korea ranks the fourth and Australia ranks the 
fifth with the frequency 156. It indicates that progress has been achieved in these countries on BIM research. It can also be seen that European and Asian countries attach great importance to the development of BIM, and that they actively carry out relevant researches in the field of BIM.

In addition, in the area of international cooperation, Canadian researchers have cooperated extensively with researchers from Australia, South Korea, Finland and other countries. The U.K., New Zealand and Germany are connected by relatively thick golden/red lines, indicating a strong partnership between these countries in 2018 and 2019.

Furthermore, nodes with high betweenness centrality have been identified with purple outer rings. As shown in Figure.5, the representative countries/regions include New Zealand (centrality = 1.25 ), the United Kingdom (centrality $=0.84$ ), Malaysia (centrality $=0.68)$, Canada (centrality $=0.64$ ) and Israel (centrality $=0.63$ ). These countries with nodes of high betweenness centrality play an important role in BIM research.

As for citation burst detection, the following 5 countries received citation bursts with different strengths at different times. Ranking according to the burst strength, the sequencing is as follows: the United States (strength $=10.49,2004-2012)$, Israel (strength $=5.31,2009-2010)$, Germany $($ strength $=$ 4.01, 2009-2011), Italy (Strength $=3.65,2017-2019$ ), and Finland (strength $=3.26,2009-2015$ ).

\subsubsection{Network of research institutes}

Other than the distribution network of countries/regions, the network of the research institutes in the field of BIM were established as well. It includes 195 nodes and 240 links in total, as shown in Figure.7.

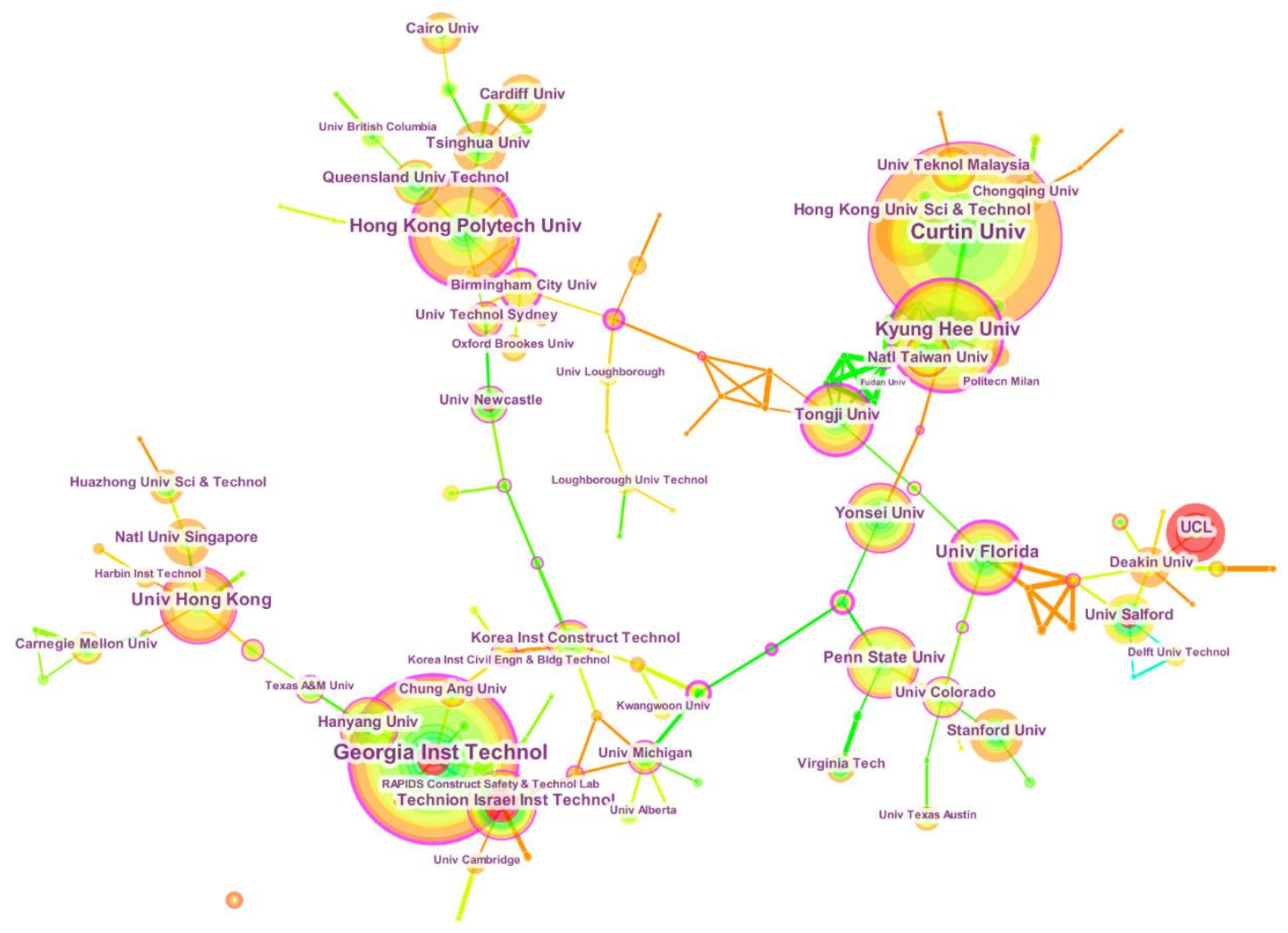


It can be found in Figure.6 that the frequency (Circle) of Curtin University is the highest. It has published the most articles in the field of BIM with absolutely high research strength, followed by Georgia Institute of Technology in the USA, Kyung Hee University in South Korea and Hong Kong Polytechnic University in Hong Kong. It is implicates that the four institutions have strong research potential in BIM. It is observed that half of the top 10 research institutes are located in Asia, which can be seen merely from the volume of publications. In recent years, BIM has been widely concerned and actively studied in Asia.

Additionally, the cooperation between different institutes is explored, as shown in Figure.6. The node is the name of the research institutes. The connection between nodes is used to describe the collaboration strength of different research institutes. The color of the connection indicates the time of the first collaboration of the node. The thickness of the connection indicates the collaboration times between the institutes. The thinner the lines are, the fewer times of cooperation there are. Hong Kong Polytechnic University has established extensive collaboration with a number of research institutes in the field of BIM such as Tsinghua University, Queensland University Technology and the Birmingham City University. University of Florida, University of Oklahoma, University North Carolina Charlotte, Calif State University Fresno and DKS Informat Consulting LLC have jointly formed a research group for close collaboration in 2018, these research institutes were connected by thicken golden lines.

Furthermore, high betweenness centrality points were identified and displayed by purple outer rings, representative research institutes of which were Hong Kong Polytechnic University (centrality $=0.26$ ), University of Washington (centrality $=0.24$, Research institutions such as Tongji University (centrality $=0.23$ ) Georgia Institute of tech (centrality $=0.22$ ) and Kyung Hee University (centrality = 0.20). These research institutes with high betweenness centrality are the hub nodes connected with other research institutes and different clusters.

In terms of citation burst, seven research institutes have received varied strength of citation burst at different time. According to the burst strength, the sequences were Georgia Institution of Technology (strength $=6.63,2006-2012)$, Technion-Israel Institute of Technology (strength $=6.57$, 2009-2013), University of Salford (strength $=5.69,2007-2012)$ and University of Newcastle (strength = 4.26, 2011-2013), UCL (strength = 3.62, 2017-2019), Virginia Polytechnic Institue and State University (strength $=2.98,2011-2013$ ) and University of Reading (strength $=2.98,2013-2014)$.

\subsection{Co-word analysis}

With more and more countries and research institutes focusing on BIM research, there are various researches on different topics, subjects and keywords. Co-word analysis aims to study the internal correlation and scientific structure of the literature through the statistical analysis of the keywords that reflect the subject of the literature. Co-word can help to estimate trends and conduct front research.

\subsubsection{Network of co-occurring subject categories}

Each journal publication from Web of Science Core Collection database is assigned to one or more subject categories based on relevant journals. A network of subject category research was generated with 62 nodes and 135 links. This network was used to analyze the emerging trend of BIM research, as shown in Figure.7. 


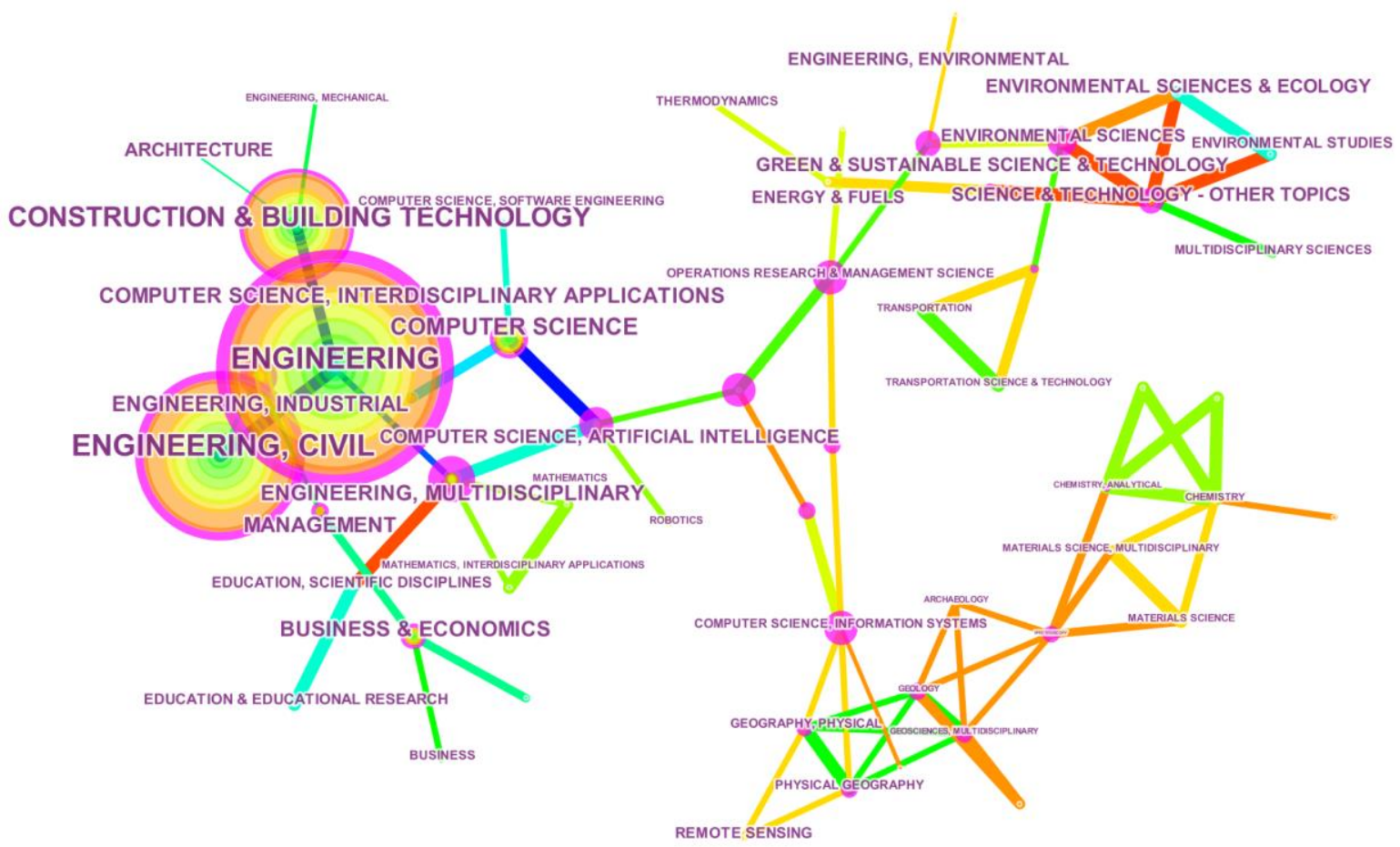

Figure.7: Network of co-occurring subject categories

In Figure. 7, the node size represents the number of articles in each category. Among them, the frequency of Engineering is the highest, followed by Engineering Civil, Construction \& Building Technology, Computer Science, Engineering, Multidisciplinary and Engineering Industry. It manifests that most of BIM articles were assigned to these categories.

It should also be noted that, in the past two years, subjects like Green \& Sustainable science and technology, Science and Technology-Other Topics and Environmental Studies have also attracted the attention of scholars. What's worth mentioning is that there are 58 articles in the category of Green \& Sustainable Science/Technology and 187 articles about computer science. Thus, it implies that the potential of BIM in energy and environmental analysis and sustainable design has been recognized and attached with great importance by the academic community.

Furthermore, nodes with high betweenness centrality were highlighted by purple outer rings , representative categories of which were computer science, artificial intelligence (centrality $=0.80$ ), engineering, electrical \& electronic (centrality $=0.76$ ), computer science, information systems (centrality $=0.68)$ engineering, multidisciplinary (centrality $=0.66$ ), and operations research \& management science (centrality $=0.65$ ). They represent the turning point connecting different stages of research, which has a significant impact on the development of BIM research.

Nine categories have received citation burst of different strengths at different time. According to the burst strength, the sequences were Green \& Sustainable Science \& Technology (burst strength $=7.53$, 2017-2019), Remote Sensing (burst strength $=6.19,2017-2019$ ), other topics of Science \& Technology (burst strength $=5.72,2017-2019$ ), Architecture (burst strength $=5.41,2004-2019$ ), Geography, Physical (burst Strength $=5.16,2017-2019$ ), Physical Geography (burst strength $=5.16$, 2017-2019), Robotics (burst strength $=4.89,2014-2015$ ) and Engineering, Environmental (Burst Strength $=3.70,2017-2019)$. It indicates that these categories of publications are on behalf of the most active fields in the research and development of BIM. 
Keywords play a role in highly summarizing the content of literature researches. To a certain extent, they represent the research content of an article. The centrality of network nodes is one of the key indexes reflecting the core degree of nodes, which can be used to measure the importance of some node in the network as well as its correlation with other nodes. Therefore, the core issue or the focus of researches that scientific researchers commonly concerned can be reflected by the keywords with high centrality and frequency. There are two types of keywords in the literature database of Web of Science: "author keyword" provided by the authors and "keyword +" identified by journals. The cooccurring keyword network is constructed by the two types of keywords in bibliographic records. There are similar keywords in all bibliographic records, such as "BIM", "building information modeling", " Building information modelling", " building information modeling (BIM) ", and "Building information modelling (BIM)". The function of merging similar keywords in CiteSpace is used to merge these similar keywords to the "Building Information Model".

When analyzing the research hotspots of BIM, the network node was set to "Keyword", and the synonymous keywords were merged after running the software to obtain the keyword co-occurring network in the research literature, as shown in Figure. 8. Each keyword in the map was represented by a square node. A larger block size represents a higher frequency of the keyword shown in the field of BIM research, therefore, they are high frequency keywords. What needs to be concerned is the square node with purplish red light which represents a high centrality of keywords and its close correlation with other keywords. For this, there were 160 nodes and 516 links in the co-occurring network. 


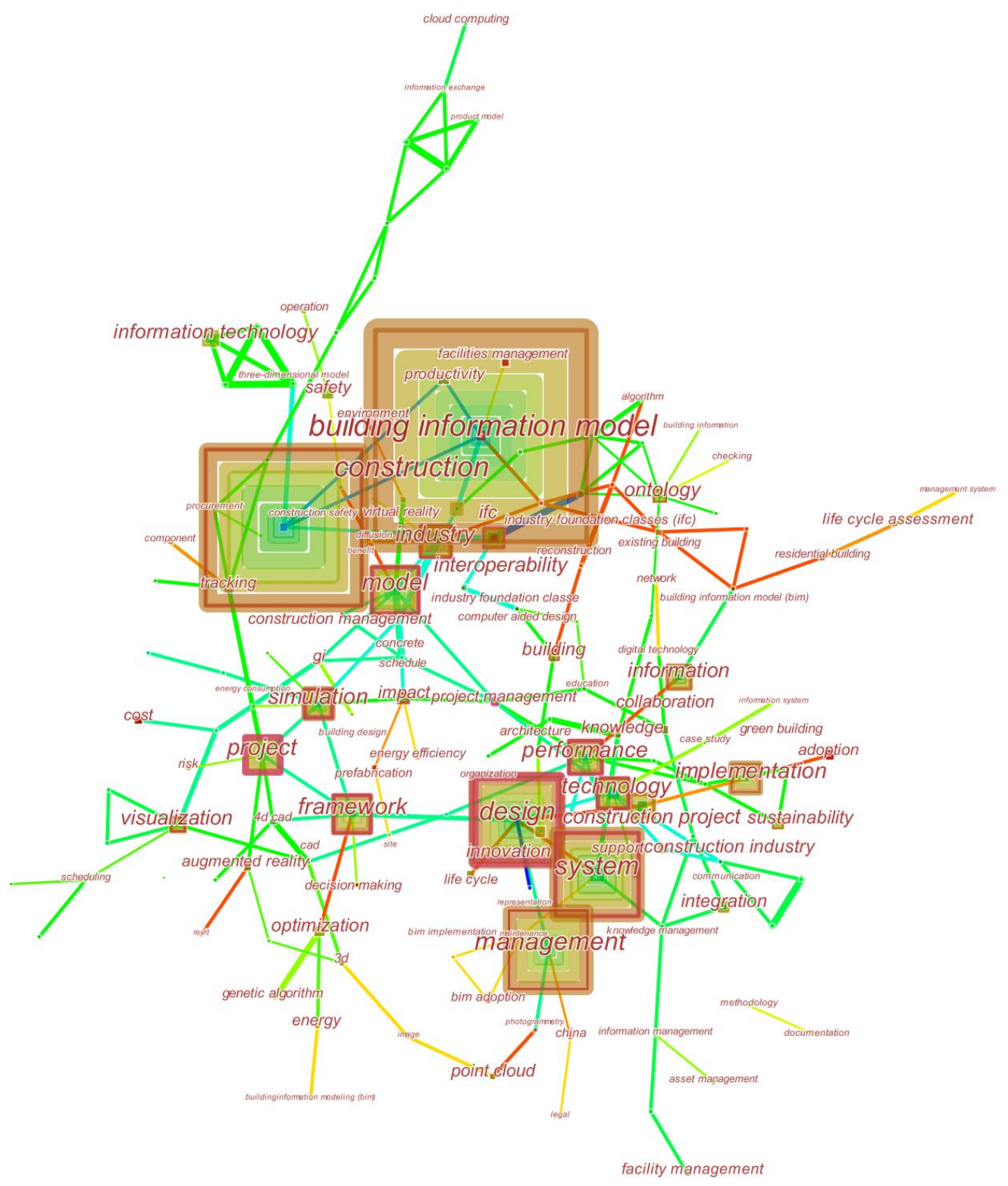

Figure.8: Network of co-occurring keywords

Table.7: High Frequency keyword of BIM research from 2004-2019

\begin{tabular}{lllll}
\hline \multirow{2}{*}{ SN } & \multicolumn{2}{l}{ Keyword with high frequency } & & \multicolumn{2}{l}{ Keyword with high centrality } \\
\cline { 2 - 4 } & Keyword name & Frequency & Keyword name & Centrality \\
\hline
\end{tabular}

The keywords with high frequency and high centrality in BIM research literature in the recent decade are shown in Table.7. The top 10 keywords in the literature were Building Information Model $($ frequency $=738)$, Construction (frequency $=359)$, Design (frequency $=213)$, System $($ frequency $=195)$, Management (frequency $=190)$, Model (frequency =138), Framework (frequency = 97), Project (frequency $=95$ ), Industry (frequency $=87$ ), and Performance (frequency $=85$ ). Combined with high centrality keywords, we can find that the hot areas of global BIM research in the recent decade include design, project, framework, industry and model. Keywords with high betweenness centrality are correlated with different research subjects, which have a significant impact on the development of BIM research as well. 


\begin{tabular}{lllll}
\hline 1 & Building Information Model & 738 & Design & 0.66 \\
2 & Construction & 359 & Project & 0.42 \\
3 & Design & 213 & Framework & 0.39 \\
4 & System & 195 & Project Management & 0.34 \\
5 & Management & 190 & System & 0.32 \\
6 & Model & 138 & Simulation & 0.32 \\
7 & Framework & 97 & Interoperability & 0.29 \\
8 & Project & 95 & Tracking & 0.29 \\
9 & Industry & 87 & Industry & 0.27 \\
10 & Performance & 85 & Model & 0.25 \\
\hline
\end{tabular}

Besides, citation burst was observed in the following eight keywords: Building information model (burst strength $=11.66,2008-2014$ ), Adoption (burst strength $=5.80,2017-2019$ ), Interoperability (Burst strength $=5.63,2007-2013$ ), 4D CAD (burst strength $=4.57,2011-2014$ ), Cloud Computing (burst strength $=4.38,2012-2014$ ), Generic Algorithm (burst strength $=4.26,2014-2016$ ), Energy Efficiency (burst strength $=4.25,2014-2016$ ) and Augmented Reality (burst strength $=4.04$, 2013-2015), indicating that these are the hotspots of BIM research in corresponding years.

Clustering in data mining is a process of aggregating and classifying data in complex networks according to similarity. In keyword clustering analysis, the similarity of nodes in the network is reflected, which is conducive to identify and detect representative knowledge subgroups in a certain field of research, that is, the hot subject in the research field. The network node is set to "Keyword" For clustering on the basis of the generation of keyword co-occurring network. Finally, the keyword clustering network in the field of BIM research is obtained, as shown in Figure. 9.

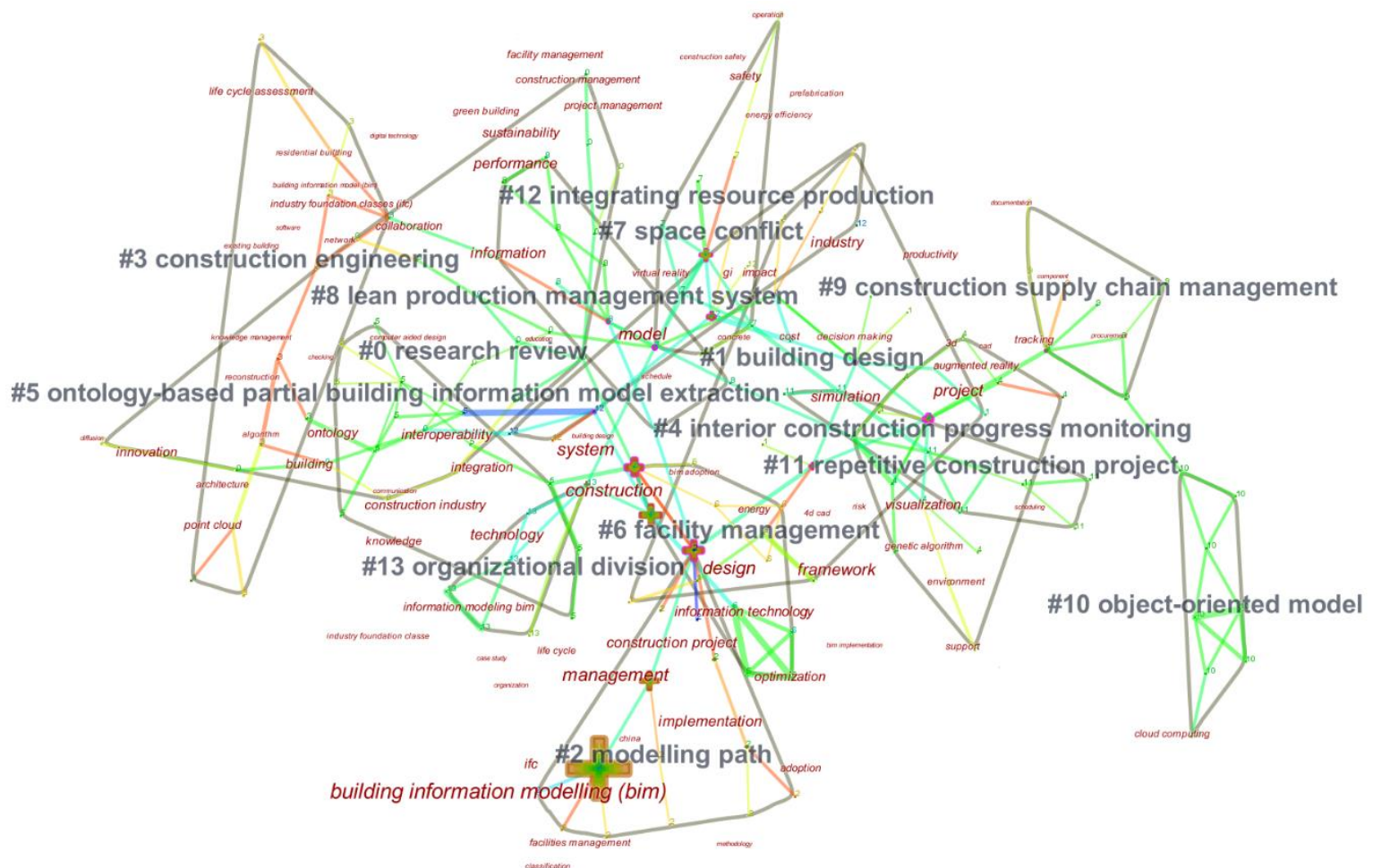




\subsection{Co-Citation analysis}

When two documents are cited by a third document simultaneously, there will be co-citation relationship between the two documents[4,16]. The citation frequency of literature can objectively reflect the degree to which the literature can be recognized by the academic community or the knowledge domain, as well as the position of the literature in the network. Continuously highly cited literature is considered classical in a certain field, while the early foundational literature and seminal literature in a field could reflect the development and research basis of the researches in that field. CiteSpace software was used in this section to perform co-citation analysis of journals, authors and documents. BIM's co-citation network was generated, in which the meaning of the size and color of the nodes and the thickness and color of the links are similar to the interpretation of the previous networks.

\subsubsection{Journal co-citation network}

The journal co-citation network in the field of BIM was established using CiteSpace software. There were 261 nodes and 644 links in the network.

As shown in Figure.10, the five most influential journals were Automation in Construction (frequency $=1071$ ), Journal of Construction Engineering and Management (frequency $=548$ ), BIM 


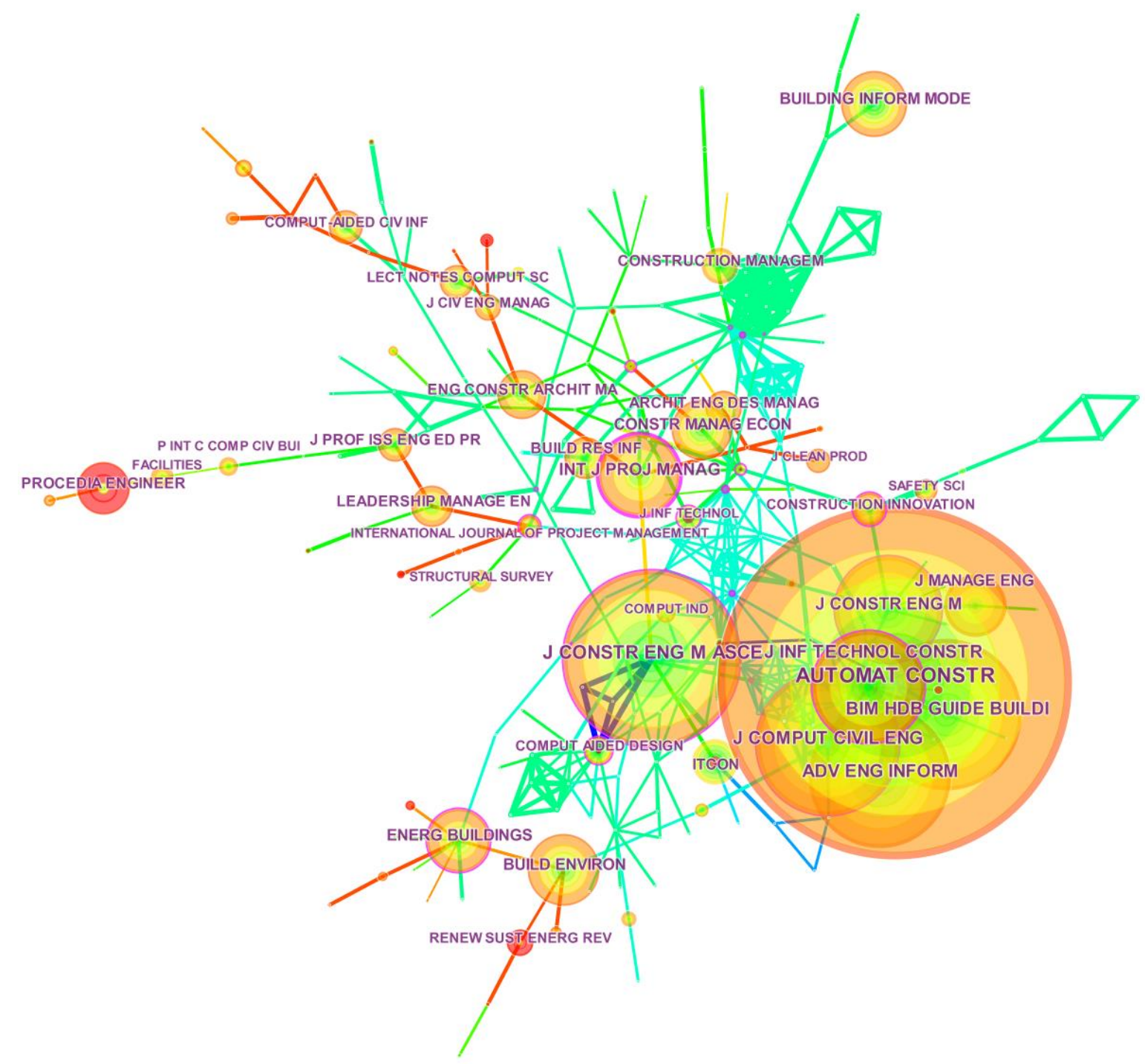

Figure.10: Journal co-citation network

As shown clearly in Figure.10, some nodes with high betweenness centrality were highlighted with purple rings, such as International Journal of Project Management (centrality $=0.22$ ), Journal of Construction Engineering and Management (centrality $=0.20$ ) and Energy and Buildings (centrality $=0.11$ ). These journals represent major academic turning points and interrelated journals published at different stages.

In addition, citation burst was found in the following representative journals in turn: Journal of Information Technology in Construction (burst strength $=19.09,2008-2013$ ), Automation In Construction (burst strength $=18.5,2006-2014$ ), Building Product Models: Building Product Models: Computer Environments, Supporting Design and Construction (Book) (burst strength $=14.63,2005$ 2012), Cost Analysis of Inadequate Interoperability in the US Capital Facilities Industry (Book) (burst strength $=8.12,2009-2014$ ) and Computer-Aided Design (burst strength $=8.05,2006-2013$ ). It shows that the articles published on these journals were widely cited in a short period of time, therefore, they are worthy of paying attention to.

\subsubsection{Author co-citation network}

Author co-citation analysis can be used to identify the relationship between the authors cited in the same article and analyze the evolution of the research group. The author co-citation network in 
512

513

514

the field of BIM is shown in Figure.11, consisting of 308 nodes and 757 links. The meaning of the size and color of nodes as well as the thickness and color of links in the map is interpreted similarly to that of the previous map.

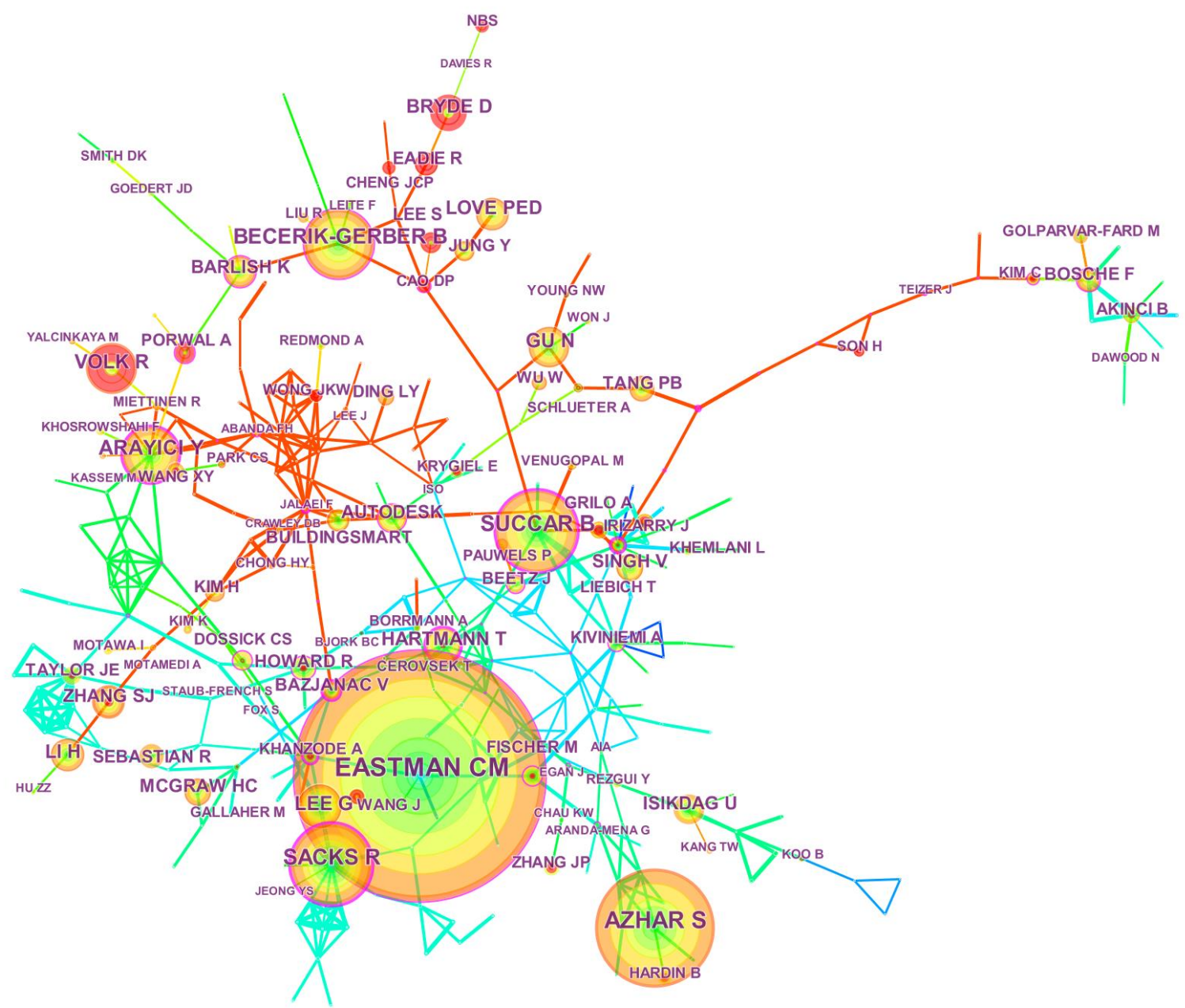

Figure.11: Author co-citation network

Seen from the figure, the top 10 authors were Charles M. Eastman (frequency $=621$, USA), Salman Azhar (frequency = 300, USA), Rafael Sacks (frequency = 212, Israel), Bilal Succar (frequency = 208, Australia), Burcin Becerik-Gerber (frequency = 184, USA), Yusuf Arayici (frequency $=145$, Turkey), Rebekka Volk (frequency =127, Germany), Ghang Lee (frequency = 125, South Korea), Ning $\mathrm{Gu}$ (frequency = 115, Australia), and Heng Li (frequency=100, Hong Kong). The diversity of the most cited authors' locations indicates that BIM research has been widely carried out around the world.

Authors with high betweenness centrality were also identified with purple rings. The nodes with purple rings means that the authors enjoy high betweenness centrality, representative authors of which are Arayici $Y$ (centrality $=0.25)$, Succar B. (centrality $=0.24)$, Sacks $R($ centrality $=0.23$ ), etc. They are the main intellectual drivers of BIM research and interrelated research in different research groups.

Several authors have experienced citation burst with the frequency of citations increasing rapidly in a short period of time. According to citation burst strength, the top five authors are Michael P. Gallaher (burst strength $=10.8136,2009-2014$ ), Lachmi Khemlani (burst strength $=10.59$ 2009-2013), Kiviniemi Arto (burst strength $=10.26,2007-2012$ ), Bo-Christer Björk (burst strength $=8.27,2009-2012$ ) and Bonsang Koo (burst strength $=7.86,2009-2014$ ). These authors may usually affect the direction of BIM research, thus their articles are worthy of paying attention to. 


\section{5}

536

537

538

539

540

541

542

543

544

\subsubsection{Document co-citation network}

Document co-citation analysis can be used to analyze the underlying structure of a knowledge field and show the number and authority of citations. During the analysis of this document cocitation, the co-citation clusters were also confirmed by CiteSpace. The document co-citation network is shown in Figure.12, with 394 nodes and 851 links. Each node represents a document and is marked with the name of the first author and the year of publication. Each link represents the co-citation relationship between two corresponding documents. The node size shows the co-citation frequency of documents. Documents with high betweenness centrality and citation burst were highlighted by purple rings and red rings, respectively.

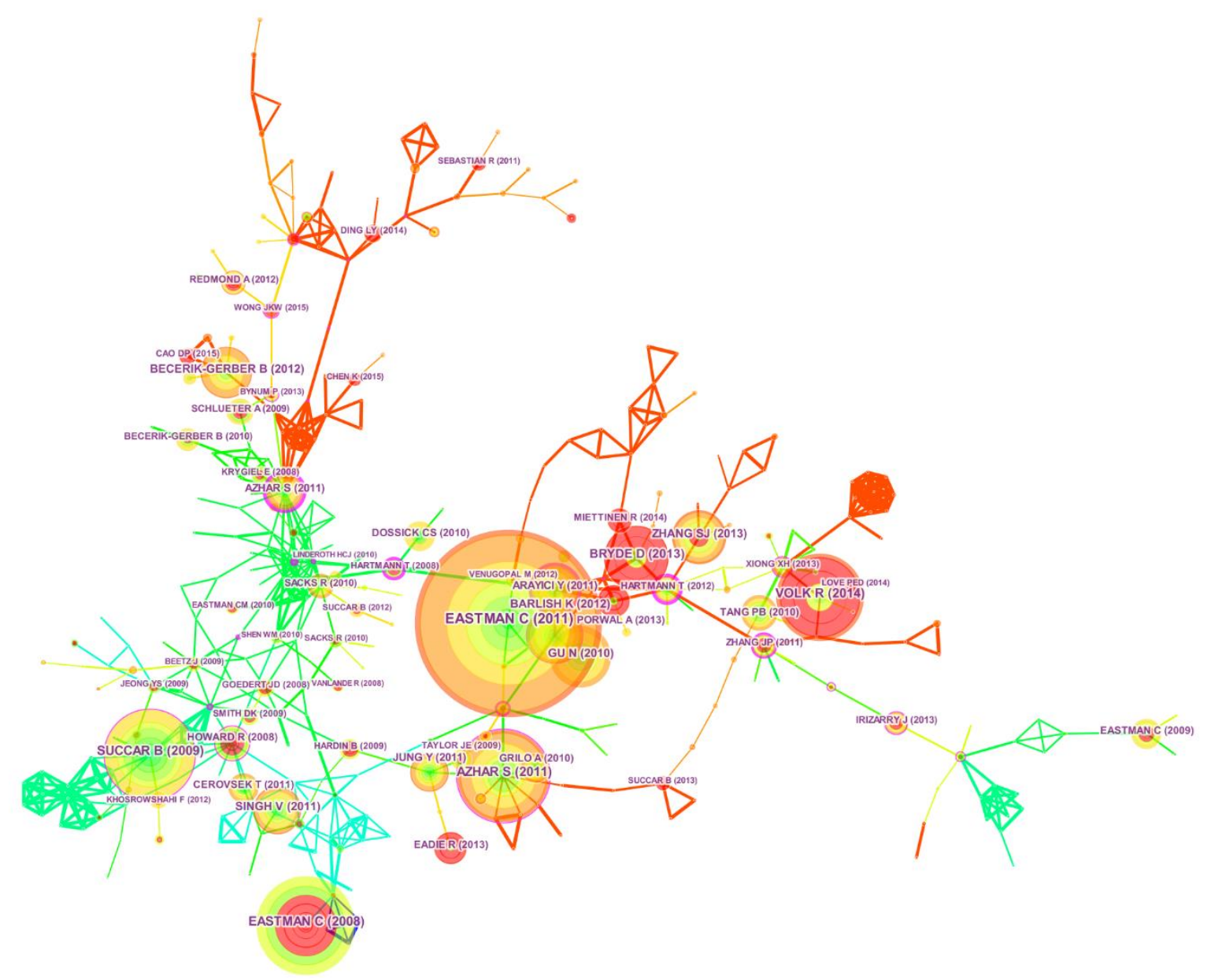

Figure.12: Document co-citation network

As shown in Figure.12, the 2011 and 2008 versions of BIM Handbook [22][45] published by Charles M. Eastman et al. received 266 and 143 co-citations, respectively, followed by 134 co-citations of Salman Azhar [2], 130 co-citations of Bilal Succar[24] and 129 co-citations of Rebekka Volk[25]. These articles are worthy of paying attention to. Representative documents with high betweenness centrality were Arayici Y et al. [26](centrality = 0.52), Timo Hartmann et al. [27] (centrality =0.49), Salman Azhar[28] (centrality = 0.46), Timo Hartmann et al. [29](centrality =0.46) and Stefan Boddy et al. [29](centrality $=0.40)$. 
A number of documents have received citation bursts, of which the representative ones include Charles M. Eastman (burst strength = 19.65, 2009-2015), Rob Howard et al.[30] (burst strength = 9.78,2010-2015), Timo Hartmannt [27] (burst strength = 7.86, 2011-2015), Rafeal Sacks et al. [31] (burst strength $=6.92,2006-2012$ ) and Rafael Sacks [32] (Burst Strength $=6.55,2012-2014)$, which indicates that there was a significant increase in the number of citations of these documents over a short period of time in the corresponding years.

\section{A revolution in global BIM research}

BIM Technology is a revolutionary development that is rapidly reshaping the AEC industry and transforming the way we build. This aim of this section is to identify the significant co-citation clusters to determine the key or anchor representative research and categorize the global BIM research over the past 16 years into 3 stages, namely: infancy stage, maturity stage and expansion stage.

As the core and essence of articles, keywords could highly summarize research hotspots directions and topics[33]. A significant function of CiteSpace is to probe the research hotspots in related fields by analyzing keyword frequencies[33].There are three cluster analysis algorithms in CiteSpace, namely, latent semantic indexing (LSI), loglikelihood ratio (LLR) and mutual information (MI). In this study, LLR algorithm was used to select the optimal cluster label according to uniqueness and coverage, which was also recommended by Chen Chaomei [34].

Based on the keywords of the documents cited in each cluster, a total of 12 significant co-citation clusters were identified, as illustrated in Figure.13. There were 40 members in\#0 "building information model", which was the largest. The number in cluster \#11 "total construction as-built documentation" was the smallest, with only 5 members.

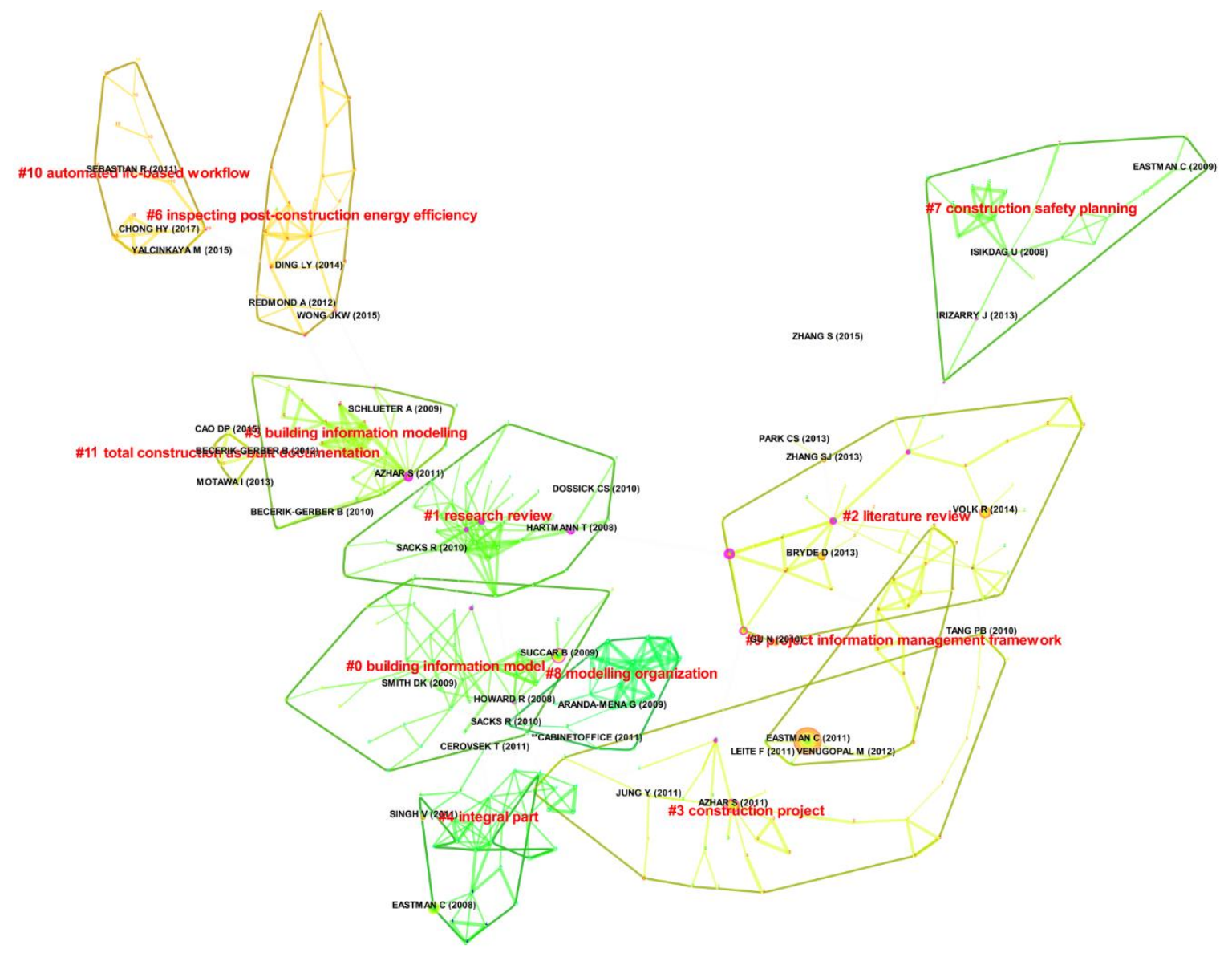

Figure.13: Document co-citation network- Clusters analysis 
The top three representative articles in each cluster were also shown in Figure.13, for instance, In Cluster\#7 Construction safety planning, the top three representative articles were Chuck Eastman et al. [35], Javier Irizarry et al. [36] and Umit Isikdag et al. [37].Alternative tags with the second and third highest LLR scores were also shown in Table.8, clusters of which were sorted by size (i.e. the number of documents/members).

Sihouette metric in clusters was used to measure the average homogeneity of the clusters. A high silhouette score indicates high consistency of cluster members in clusters of similar sizes. The score range of the above 11 clusters was between 0.858 and 0.996 , suggesting high consistency of members in each cluster. Mean year of publications suggests whether the cluster consists of the latest published documents or the old ones, through which it can be found that Cluster \#4 "integral part" consists of old documents, while Cluster $\# 6$ and $\# 10$ consist of new documents. In addition, representative documents of each cluster refer to the top three documents with most co-citation frequency in a cluster. These representative documents have a profound impact on the label of the cluster, which is worthy of paying attention to.

Table.8: Co-citation clusters of BIM research in 2004 - 2019

\begin{tabular}{|c|c|c|c|c|c|c|c|}
\hline $\begin{array}{l}\text { Cluster } \\
\text { ID }\end{array}$ & Size & Silhouette & $\begin{array}{l}\text { Mean } \\
\text { (Year) }\end{array}$ & $\begin{array}{l}\text { Cluster Label } \\
\text { (LLR) }\end{array}$ & $\begin{array}{l}\text { 1st Alternative } \\
\text { Label }\end{array}$ & $\begin{array}{l}\text { 2nd } \\
\text { Alternative } \\
\text { Label }\end{array}$ & $\begin{array}{l}\text { Representative } \\
\text { documents }\end{array}$ \\
\hline$\# 0$ & 40 & 0.858 & 2008 & $\begin{array}{l}\text { building } \\
\text { information } \\
\text { model }\end{array}$ & $\begin{array}{l}\text { multi-standpoint } \\
\text { framework }\end{array}$ & $\begin{array}{l}\text { technological } \\
\text { development }\end{array}$ & $\begin{array}{l}\text { Succar Bilal [24] } \\
\text { Rob Howard et al [30] } \\
\text { James D.Goedert et al } \\
\text { [38] } \\
\text { Dana K. Smith et al[39] }\end{array}$ \\
\hline$\# 1$ & 36 & 0.94 & 2008 & $\begin{array}{l}\text { research } \\
\text { review }\end{array}$ & symphony & $\begin{array}{l}\text { digital } \\
\text { construction } \\
\text { design }\end{array}$ & $\begin{array}{l}\text { Carrie S. Dossick et al } \\
\text { [40] } \\
\text { Rafael Sacks et al[41] } \\
\text { Timo Hartmann et al } \\
\text { [27] }\end{array}$ \\
\hline$\# 2$ & 33 & 0.913 & 2012 & $\begin{array}{l}\text { literature } \\
\text { review }\end{array}$ & $\begin{array}{l}\text { project } \\
\text { information } \\
\text { management } \\
\text { framework }\end{array}$ & $\begin{array}{l}\text { automated } \\
\text { monitoring }\end{array}$ & $\begin{array}{l}\text { Rebekka Volk et al [25] } \\
\text { David Bryde et al [42] } \\
\text { Ning Gu et al [43] }\end{array}$ \\
\hline$\# 3$ & 31 & 0.88 & 2012 & $\begin{array}{l}\text { construction } \\
\text { project }\end{array}$ & $\begin{array}{l}\text { project } \\
\text { information } \\
\text { management } \\
\text { framework }\end{array}$ & $\begin{array}{l}\text { operational } \\
\text { critical success } \\
\text { factor }\end{array}$ & $\begin{array}{l}\text { Salman Azhar et al [44] } \\
\text { Youngsoo Jung et al [45] } \\
\text { Pingbo Tang et al [46] }\end{array}$ \\
\hline$\# 4$ & 28 & 0.945 & 2006 & integral part & $\begin{array}{l}\text { civil engineering } \\
\text { education }\end{array}$ & $\begin{array}{l}\text { teaching } \\
\text { building } \\
\text { information } \\
\text { modeling }\end{array}$ & $\begin{array}{l}\text { Chuck Eastman et al[47] } \\
\text { Vishal Singh et al [48] } \\
\text { Tomo Cerovsek [49] }\end{array}$ \\
\hline \#5 & 27 & 0.912 & 2012 & $\begin{array}{l}\text { building } \\
\text { information } \\
\text { modelling }\end{array}$ & green building & $\begin{array}{l}\text { project } \\
\text { information } \\
\text { management } \\
\text { framework }\end{array}$ & $\begin{array}{l}\text { Salman Azhar et al[50] } \\
\text { Arno Schlueter et al [51] } \\
\text { Burcin Becerik-Gerber } \\
\text { et al [52] }\end{array}$ \\
\hline$\# 6$ & 24 & 0.934 & 2015 & $\begin{array}{l}\text { inspecting } \\
\text { post- } \\
\text { construction }\end{array}$ & $\begin{array}{l}\text { Life cycle } \\
\text { assessment }\end{array}$ & $\begin{array}{l}\text { environmental } \\
\text { potential }\end{array}$ & $\begin{array}{l}\text { Alan Redmond et al } \\
\text { [53] } \\
\text { Johnny }\end{array}$ \\
\hline
\end{tabular}




\begin{tabular}{|c|c|c|c|c|c|c|c|}
\hline & & & & $\begin{array}{l}\text { energy } \\
\text { efficiency }\end{array}$ & & & $\begin{array}{l}\text { Lieyun Ding et al [54] } \\
\text { Kwok Wai Wong et al } \\
\text { [55] }\end{array}$ \\
\hline \#7 & 23 & 0.969 & 2008 & $\begin{array}{l}\text { construction } \\
\text { safety } \\
\text { planning }\end{array}$ & $\begin{array}{l}\text { geographic } \\
\text { information } \\
\text { system }\end{array}$ & space conflict & $\begin{array}{l}\text { Chuck Eastman et al } \\
\text { [35] } \\
\text { Javier Irizarry et al [36] } \\
\text { Umit Isikdag et al [37] }\end{array}$ \\
\hline$\# 8$ & 21 & 0.924 & 2008 & $\begin{array}{l}\text { modelling } \\
\text { organization }\end{array}$ & $\begin{array}{l}\text { structural } \\
\text { adjustment }\end{array}$ & pilot study & $\begin{array}{l}\text { Rafael Sacks [56] } \\
\text { Cabinet Office [57] } \\
\text { Guillermo Aranda- } \\
\text { Mena et al [58] }\end{array}$ \\
\hline \#9 & 18 & 0.982 & 2014 & $\begin{array}{l}\text { project } \\
\text { information } \\
\text { management } \\
\text { framework }\end{array}$ & $\begin{array}{l}\text { construction } \\
\text { project }\end{array}$ & $\begin{array}{l}\text { building } \\
\text { information } \\
\text { modelling }\end{array}$ & $\begin{array}{l}\text { Chuck Eastman et al[47] } \\
\text { M. Venugopal et al [23] } \\
\text { Jim Steel et al [59] }\end{array}$ \\
\hline$\# 10$ & 14 & 0.985 & 2015 & $\begin{array}{l}\text { automated ifc- } \\
\text { based } \\
\text { workflow }\end{array}$ & $\begin{array}{l}\text { diagnosis } \\
\text { approach }\end{array}$ & $\begin{array}{l}\text { auto-deployed } \\
\text { model-based } \\
\text { fault detection }\end{array}$ & $\begin{array}{l}\text { Rizal Sebastian[60] } \\
\text { Mehmet Yalcinkaya et } \\
\text { al[61] } \\
\text { Heap-Yih Chong et al } \\
\text { [62] }\end{array}$ \\
\hline \#11 & 5 & 0.99 & 2014 & $\begin{array}{l}\text { total } \\
\text { construction } \\
\text { as-built } \\
\text { documentatio } \\
\mathrm{n}\end{array}$ & lift planning & benefit sharing & $\begin{array}{l}\text { Burcin Becerik-Gerber } \\
\text { et al [63] } \\
\text { Dongping Cao et al [64] } \\
\text { Ibrahim Motawa et al } \\
\text { [65] }\end{array}$ \\
\hline
\end{tabular}

Note: rows for clusters $\# 0, \# 1, \# 2, \# 3, \# 4$ and $\# 9$ are classified to the formulating stage; rows for clusters $\# 5, \# 6, \# 7$ and $\# 8$, to the accelerating stage, and clusters \#10 and \# 11 to the transforming stage.

\subsection{Evolution of global BIM research}

Clustering or cluster analysis is the task of grouping a set of objects in such a way that objects in the same group (called a cluster) are more similar in traits or features to each other than to those in other groups. It is an iterative process of knowledge discovery, or interactive multi-objective optimization that involves trial and error. There are a handful types of clustering, such as strict partitioning clustering, strict partitioning clustering with outliers, overlapping clustering, hierarchical clustering and subspace clustering. Strict partitioning clustering with outliers, which is a type of hard clustering is adopted in this section of our study. These clusters, which are formed based on document co-citation, and namely the formulating stage, accelerating stage and transforming stage, are distinguished by the cluster labels of global BIM research. The cluster labels are used as a proxy to determine the diffusion of innovation or technology adoption stage. For cluster $\# 0,1,2,3,4$ and 9, it can be inferred that the research has been expanded and translated to industry practice, ; for cluster $\$ 5,6,7$ and 8 , it can be inferred that the research direction is at the accelerate stage, suggested by early to early majority adoption of the knowledge or technology; for cluster \#10 and 11,

612 stage, as illustrated in Figure.14. 


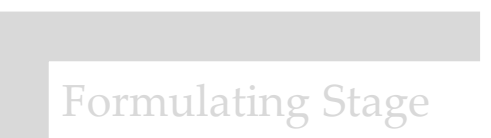

Formulating the foundation for creating theoretical framework that forms the basis for global BIM research.

Research has been expanded and translated to industry practice, such as research review, framewrok development and etc.

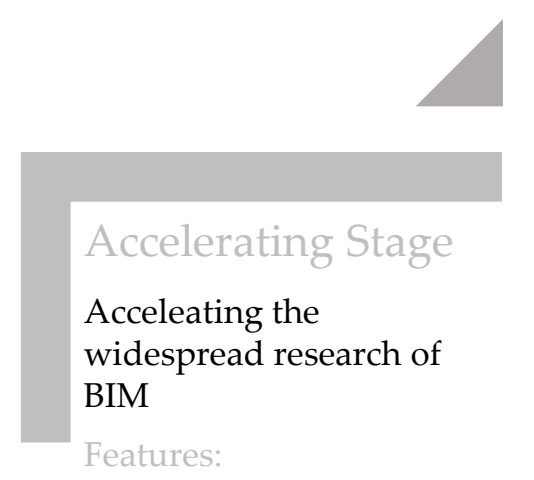

Early majority adoption of the knowledge or technology, such as integrating with Green Building assessment, GIS, rule-based checking and etc.

Cluster $\# 5,6,7 \& 8$
Transforming Stage

Transforming the AEC industry with potential emerging technologies

Features:

Innovative and at a nascent, such as ICT, FM and etc.

Cluster \#10 \& 11

Figure.14: Evolution of global BIM research

\subsection{Formulating stage}

Formulating stage means formulate the foundation for creating theoretical framework that forms the basis for global BIM research. At this stage, research themes are summarized in the following aspects: 1) Research review in BIM; 2) Conceptual BIM framework; and; 3) Building BIM capability.

\subsubsection{Formulating stage - Research Review}

There were 40 members in Cluster \#1 "Research Review". The top three representative articles were published by Carrie S. Dossick [40], Rafael Sacks [41] and Timo Hartmann [27], all of which were published on the "Journal of Construction Engineering and Management". Carrie S. Dossick et al. [40] (frequency $=46$ ) reviewed related work on what caused successful technology adoption both in the AEC industry and in general. The application of BIM technology in MEP coordination as well as how the cooperation and communication are affected by introduction of BIM were also studied by them. Their findings show that the BIM-enable projects are often technically coupled but with organizational differences. It also suggests that organization power and structure should be considered for the successful performance of BIM. Rafael Sacks et al. [41] (frequency $=39$ ) reviewed different concepts and BIM of lean construction in the life cycle of the whole projects. On this basis, an analytical framework or classification was established to evaluate the interrelationship between lean construction and BIM. Timo Hartmann et al. [27] (frequency = 27) qualitatively summarized and reviewed the results of 26 case studies applying 3D/4D models to construction projects, showing researchers and practitioners the challenges of applying 3D/4D model to projects. The challenges faced by $3 \mathrm{D} / 4 \mathrm{D}$ models in test cases by practitioners were elaborated by them as well. The main analytical results show that project practitioners in most of the test cases use the model only in one application domain. In this article, it suggests that further research is needed on how to integrate 
3D/4D model technology into the work and business processes conducted by project teams, thereby making wider use of the 3D/4D models throughout the life cycle of the project.

There were 33 members in Cluster \#2 "literature review". The top three representative articles were published by Rebekka Volk [25], David Bryde [42] and Ning Gu [43]. Rebekka Volk et al. [25] (frequency $=27$ ) reviewed more than 180 articles on BIM for existing buildings. The results show that the lack of implementation of BIM for existing buildings is caused by the following factors: (1) high modeling/transformation efforts from captured building data to semantic BIM objects, (2) the information update in BIM, (3) handling of uncertain data, objects and relationships in BIM of existing buildings. David Bryde et al. [42] carried out literature review on BIM, collected information of 35 building projects using BIM, and explored the benefit degree of BIM application to a cross-section of the construction projects. The study also provided a set of criteria for project success, using analysis to determine the degree of compliance of each project to the criteria. The study also pointed out that the most frequently reported benefits were related to cost reduction and control in the life cycle of projects, and that negative benefits were mainly concentrated on the use of BIM software. Cost/benefit analysis, awareness improvement, education and training are key responses to the challenge of BIM use. Ning Gu et al. [43] (frequency =90) did a literature review for BIM-related academic publications, white paper, technical reports from major technology providers, guidelines, online newsletters and government reports. They analyzed the present situation of BIM in the AEC industry and reevaluated its role and potential contribution in the future. This paper analyzes the preparation in (1) products, (2) processes and (3) personnel in the industry in order to locate the adoption of BIM according to the cross-domain status quo and expectation. Through the study of this paper, it suggests that there are many factors that may affect the adoption of BIM, of which the functional requirements of technical tools and non-technical strategic issues are two primary factors.

Observation 1: At formulating stage, many authors conduct research review in BIM, theoretical exploration of BIM origins, foundations, relevant theories and emerging scenarios to lay the foundation of the BIM development, such as Cluster \#1 and Cluster \#2.

\subsubsection{Formulating stage - Conceptual BIM framework}

There were 36 members in Cluster \#0 "Building Information Model". The top three representative articles were published by Succar Bilal [24], Rob Howard [30] and James D. Goedert [38] and Dana K. Smith [39]. Succar Bilal [24] (frequency = 130) explored a number of open BIM international guidelines and developed the BIM framework. Rob Howard et al. [30] (frequency = 51) discussed BIM and IFC and proposed a framework for a preliminary outline that should be developed into a precise tool with the function of case comparison. James D. Goedert et al. [38] (frequency $=29$ ) created a 3D completion model and a 4D completion model, and they attached construction process information to the models so that the owners can use them after construction. The research results show that BIM program and software need to be modified in order to obtain the construction process documents. Dana K. Smith et al. [39] (frequency $=29$ ) published a book based on strategic thinking which could help readers to understand the whole situation and refine the BIM workflow, thus showing the potential of BIM construction by all participants in the industry.

There were 31 members in Cluster \#3 "Construction Project". The top three representative articles were published by Salman Azhar [44], Youngsoo Jung [45] and Pingbo Tang [46]. Salman Azhar et al. [44] (frequency $=134$ ) mentioned that BIM could simulate construction project in a virtual environment. The prospect of BIM was also discussed by them, showing that the future of BIM was exciting and challenging. It was expected that an increasing number of BIM applications may help to strengthen the collaboration of AEC industry, reduce fragmentation, ultimately improve performance and reduce project costs. Youngsoo Jung et al. [45] (frequency $=59$ ) proposed a comprehensive BIM framework to evaluate promising areas and to identify driving factors for practical applications in real-world construction projects. Pingbo Tang et al. [46] (frequency $=54$ ) 
presented an approach that can be used to automately create the process of as-built BIMs for construction projects.

Cluster \#9 "Project Information Management Framework" contained 18 members. The top three representative articles were published by Charles M. Eastman [47], M. Venugopal [23], Jim Steel [59]. Charles M. Eastman et al. [47] (frequency $=266$ ) published the 2nd Edition, 2011 version of BIM Handbook. M. Venugopal et al. [23] (frequency $=21$ ) proposed to use model view definition (MVD) concept as an object-oriented and modular mechanism, so as to embed semantic meaning in model views. The conclusion of the paper is that Industry Foundation Classes (IFC) model lacks a formal definition of entities, attributes and relationships despite of the rich expression of the IFC product model. It suggests that the modularization and logical framework of formal specifications based on IFC concepts should be further studied to achieve standardized and reusable model views. Jim Steel et al. [59](frequency $=14$ ) presented experiences with issues of model-based interoperability in exchanging building information models between various tools, particularly using the industry standard IFC data modelling format. Fernanda Leite et al. [66](frequency=14) evaluated the modeling work related to different levels of detail generation in BIM and the role levels of development (LoD) played in supporting the design coordination of mechanical, electricity and plumbing (MEP). The results show that the total modeling time from one LoD to another increases, from doubling of the modeling work to 11 times of folding. The research shows that additional modeling work can contribute to more comprehensive analysis and better decision support in the process of design and construction.

Observation 2: Conceptual BIM framework, to develop BIM framework to satisfy the niche BIMbased application

\subsubsection{Formulating stage - Building BIM capability}

There were 28 members in Cluster \#4 "Integral Part", $1^{\text {st }}$ alternative label "Civil engineering education" and $2^{\text {nd }}$ alternative label "Teaching Building Information Modeling" The top three representative articles were published by Charles M. Eastman [47], Vishal Singh [48] and Tomo Cerovsek [49]. Charles M. Eastman et al. [47] (frequency = 143) published a BIM Handbook (2008) which brought together information about current BIM, history and potential future in a convenient location. It can be used as a convenient reference book or a technical support for buildings involved in design, construction and operation. Vishal Singh et al. [48] (frequency = 73) developed a BIM-server based multi-disciplinary integrated collaboration platform. Tomo Cerovsek [49] (frequency $=45$ ) proposed an improved method, framework and schemata of integrated BIM tools and patterns through the critical review of Building product modelling, including the development of communication standards and the characteristics of more than 150 AEC/O (building, engineering, construction and operations) tools and digital models.

Observation 3: Building BIM capability, by developing educational curriculum structure around BIMs use-case, such as Cluster 4.

\subsection{Accelerating stage}

The theoretical foundation developed under formulating stage forms the knowledge based for BIM research during the accelerating stage. Accelerating stage means accelerating the widespread research of BIM and kicking-start the transition from traditional 2D based workflow to an objectorientated workflow. At this stage, research focuses on the integration of BIM and other related technologies such as GIS, energy calculation, rule-based checking and the development of BIM application.

There were 27 members in Cluster \#5 "building information modelling". The first three representative articles were published by Salman Azhar [50] , Arno Schlueter [51] and Burcin BecerikGerber [52]. Salman Azhar et al. [50] (frequency $=56$ ) demonstrated the application of BIM in 
sustainable design and LEED® certification with real cases. The results of this study show that the documents supporting LEED credits can be compiled directly or indirectly using the results of BIMbased sustainable analysis software. Compared with traditional methods, this process simplifies the LEED ${ }^{\circledR}$ certification process and saves a lot of time and resources. Arno Schlueter et al. [51] (frequency $=39$ ) developed a BIM-based prototypical tool to support graphical visualization of instantaneous energy, energy calculations and result performance metrics. Burcin Becerik-Gerber et al.[52] (frequency $=36$ ) reviewed extensive cases and provided an anecdotal evidence to support the view that the use of BIM could make the construction process more efficient. They also presented the results of an industry-wide online survey. The aim of their study was to understand the perceived value of BIM in the American construction industry, with particular attention paid to the actual benefits and costs associated with the use of BIM at the project level.

There were 24 members in Cluster \#6 "inspecting post-construction energy efficiency". The top three representative articles were published by Alan Redmond [53], Lieyun Ding [54] and Johnny Kwok Wai Wong [55]. Alan Redmond et al. [53] (frequency = 36) put forward an integrated platform of cloud BIM using the cloud calculation as BIM application based on the semi-structured interview for 11 expert interviewees. The platform also includes applications like energy performance analysis, which was designed to identify the energy use and energy needs of HVAC partitions in the early design phase as well as BIM applications, so as to take advantage of the corresponding 3D, 4D, and 5D features. Lieyun Ding et al.[54] (frequency $=27$ ) developed a BIM application framework to outline BIM applications in the construction industry, such as project quality, safety and environmental management. The expansion process from $3 \mathrm{D}$ to computable $\mathrm{nD}$ model, especially the method of integrating safety, quality and carbon emission variables into BIM was described and analyzed as well. Johnny Kwok Wai Wong et al. [55] (Frequency=23) reviewed and compared 84 Green-BIM-related documents, of which 44 were in the design stage, 25 in the construction stage, 8 in the maintenance and retrofitting stage and 12 in the demolition stage. The authors also suggested that the use of "one-stop" BIM technology should be promoted for environmental sustainability monitoring and management throughout the life cycle of buildings in future studies. Meanwhile, the use of cloud-based BIM technology should be considered, thereby using "big data" to manage the sustainability of buildings.

There were 23 members in Cluster \#7 "construction safety planning". The top three representative articles were published by Charles M. Eastman [35] , Javier Irizarry [36] and Umit Isikdag [37]. Charles M. Eastman et al. [35] (frequency = 46) explored a rule checking system which evaluated architectural design according to different criteria, such as Building code and construction safety. It also mentioned that the rule-based checking system was still in an early stage. Javier Irizarry et al. [36] (frequency $=34$ ) integrated BIM and geographic information system (GIS) into a unique system that tracked the status of the supply chain and provided early warning signals to ensure the delivery of materials. The study of Umit Isikdag et al. [37] (frequency $=13$ ) showed that high-level geometric and semantic information obtained from BIMs can be transferred to the geospatial environment, results of which also suggest that sufficient level and quantity of geometric and semantic information related to buildings are provided by BIMs to achieve seamless automation of data management tasks in the process of location selection and fire response management.

There were 21 members in Cluster \#8 "modelling organization". The first three representative articles were published by Rafael Sacks [56], Cabinet Office [57] and Guillermo Aranda-Mena [58]. Rafael Sacks [56] (frequency $=16$ ) carried out an experimental study on BIM and product data exchange in the design and production of the building prefabricated facade. The study also showed that there are no restrictions on the use of existing software to design and refine prefabricated facade. The production of the same set of drawings shows a 57 percent increase in productivity compared to the CAD process. However, the data exchange between the building and the prefabricated engineering system is incomplete and inconsistent, which confirms the necessity of the BIM exchange standard. Current Industry Foundation Classes (IFC version 2x3) model lacks a predefined set of entities and attributes. Cabinet Office [57] (Frequency=11) is a government construction strategy published by the 
784

785

786

787

788

789

790

791

792

793

794

795

796

797

British government in an effort to improve the productivity and save costs in the construction industry. Guillermo Aranda-Mena et al. [58] (frequency $=10$ ) investigated 47 value propositions using BIM through several case studies in Australia and Hong Kong. The focus of the paper was designed on the challenges and benefits for architectural and engineering consultants. In addition, the findings were coded, interpreted and synthesized to identify the challenges and business drivers. The authors also found that the shared understanding of BIM application on business drivers ranged from commercial to high-rise building projects, especially for managing the process of design and construction.

Observation 4: At this stage, research on BIM application was revolutionized to incorporated with other technologies such as energy calculation, GIS and rule-based checking.

\subsection{Transforming stage}

Transforming the AEC industry with protentional emerging technologies and getting the stakeholders to use BIM extensively in a streamlined and integrated manner over the building life cycle.

There were 14 members in Cluster \#10 "automated IFC-based workflow". The top three representative articles were published by Rizal Sebastian [60], Mehmet Yalcinkaya [61] and HeapYih Chong [62]. Rizal Sebastian [60] (frequency = 21) proposed five success factors known as "POWER" for integrated collaborative application of BIM based on literature analysis, previous researches and case studies, including: (1) Product information sharing (P), (2) Organisational roles synergy (O), (3) Work processes coordination (W), (4) Environment for teamwork (E) and (5) Reference data consolidation (R). It is also conducive to actually discussing the changes in the roles and processes needed for developing and operating sustainable buildings with the support of integrated ICT framework and tools in science and practice. Mehmet Yalcinkaya et al. [61] (frequency $=17$ ) drew some clear conclusions through the comprehensive annotation of a large number of BIM research literature published from 2004 to 2014. Latent semantic analysis (LSA) was used to analyze the abstracts of 975 academic papers objectively, through which, 12 main research fields were revealed. Various specific research topics related to each of the main areas have been identified. These main research fields and research subjects have reflected the model and trend of BIM research. HeapYih Chong et al. [62] (frequency $=16$ ) analyzed the BIM standards, guidelines and peer- reviewed academic publications through retrospective review. The results show that there has been a lot of researches and development in the use of BIM in different stages, but few in refurbishment and demolition, which also reveals some significant insights, including (1) new BIM tools are needed for evaluation of the sustainability criteria, (2) the interoperability between BIM software and energy consumption analysis tools needs to be improved, (3) streamlining the BIM usage into refurbishment and demolition is required, and (4) there is a need for an innovative procurement system to make the society sustainably compliant with the project.

There were 5 members in Cluster \#11 "total construction as-built documentation". The top three representative articles were published by Burcin Becerik-Gerber [63], Dongping Cao [64] and Ibrahim Motawa[65]. Burcin Becerik-Gerber et al. [63] (frequency = 77) explored how BIM can be a useful platform to complement FM practices. Through online survey and face-to-face interview, the application status, potential application prospect and people's interest in application of BIM in FM were evaluated. The interaction between BIM and FM was defined by illustrating application areas and data requirements for FM practices that support BIM. The synergistic effect between the two aspects is emphasized in this paper to help professionals to identify potential areas where BIM may be useful in FM practice. Dongping Cao et al. [64] (frequency =27) analyzed the current BIM practice in China and evaluated how such practices change their effectiveness based on the investigation of 106 projects using BIM. The results also prove that the project characteristics have a significant impact on the success of BIM use. However, the more important factors affecting the effectiveness of BIM are the degree of comprehensive use and customer/owner support. The results show that the current 
833 BIM practice involves both technical and organizational issues which also provides a reference for 834 developing the potential of BIM in the industry. Ibrahim Motawa et al. [65] (frequency=19) developed 835 a knowledge-based BIM system for building maintenance, so as to help maintenance teams to learn 836 from previous experience and trace the complete history of building elements and all affected 837 elements through previous maintenance operations. The results show that the knowledge-based BIM 838 integrated system can provide advanced and useful functions for construction operations. On the 839 other hand, the knowledge management principle embedded in the system is combined with the 840 information management principle embedded in the BIM system, which suggests a direction for the 841 transition from "building information modelling" to "Building Knowledge Modelling".

Observation 5: At the transforming stage, research on BIM application was revolutionized to integrated with emerging technologies, such as ICT, FM and etc.

844

845

846

847

848

849

850

851

852

853

854

855

856

857

858

859

860

861

862

\subsection{Co-Research direction and policy implication}

Reflecting on the research in the previous three stage, various government and national bodies across globe started to formulate the national BIM implementation polices and strategies to ease BIM adoption such as evolution of BIM policy in Singapore from BIM to Virtual Design Construction (VDC) and to Integrated Digital Delivery (IDD). In Singapore, Building and Construction Authority (BCA) is the driving agency for BIM, VDC and and IDD adoption. In Nov 2010, the 1st BIM roadmap was formulated to steer the construction industry leverage on BIM technology as a mean to enable building professional to deliver their building in more sustainable and effective manner. BIM was identified as one of the key drivers to improve productivity and level of integration across various disciplines. The 1st BIM roadmap aims to realize the version of a highly integrated and technologically advanced construction sector by 2020. In 2015, The 2nd Roadmap aims to get the construction industry to extensively use BIM in a streamlined project delivery process and integrated work environment over the building lifecycle, the 2nd BIM roadmap focusing on the following 5 key strategies, as illustrated in Figure.15. Building on the momentum of the previous two Roadmaps, BCA come out the IDD plan to enlarging the digitalization and transforming the AEC industry with potential emerging technologies in year 2017. IDD aims to achieve timely, cost effectively, productive and high-quality project delivery through 4 stages, namely, design, manufacturing, fabrication and asset delivery. This made possible with the help of BIM, VDC and suitable digital solutions to convey relevant, accurate and timely digital information across the whole life cycle. 


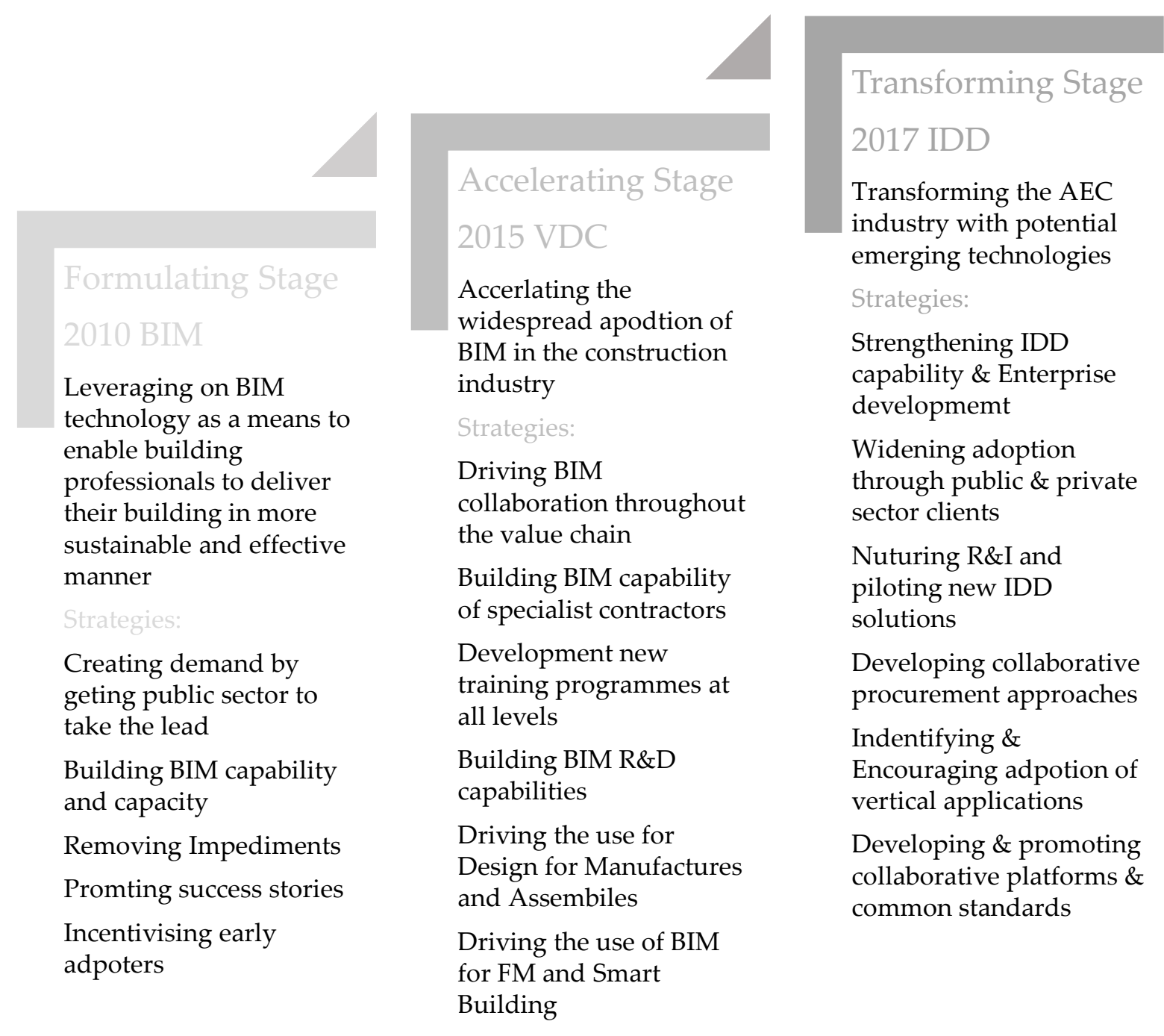

Figure.15: Evolution of BIM policy in Singapore 
Through the quantitative and qualitative analysis of global BIM research, the contributions and influence of main researchers were identified. In the field of BIM research, Xiangyu Wang, Rafael Sacks and Jack C.P. Cheng were the top three productive authors, while Charles M. Eastman, Salman Azhar and Rafael Sacks were the top three authors with high frequency of citations. In terms of the distribution of journal articles, most of the BIM articles sourced from the United States, China and the United Kingdom. In addition, Curtin University, Georgia Institute of Technology and Hong Kong Poly University were recognized as the most productive research institutes in the field of BIM. These countries and research institutes played an important role in linking research activities between different countries and institutes.

As for the classification of research disciplines, the number of published records of BIM was the most in the following three subjects, namely, Engineering, Engineering Civil and Construction \& Building Technology. However, it's also worth mentioning that a large number of scholars have been attracted by subjects like Green \& Sustainable Science and Technology in recent year. The highfrequency keywords include construction, design, system, management, model, framework, project, industry and performance. In BIM keyword analysis, the related high-frequency keywords include construction, design, system, management, model, framework, project, industry and performance. The frequency of BIM research co-citation journals is mainly concentrated in journals like Automation in construction, Journal of Information Technology in Construction, Journal of computing in civil engineering and etc. Over the past decade, the co-citation frequency and citation frequency of these journals was also very high, suggesting that they had a strong and sustained impact on BIM research.

This paper provided valuable information for researchers and practitioners by applying visualization technology to visualize the current situation in the research field of BIM. Key scholars, institutions, regions/countries and core articles were identified with the elaboration of the current situation of the research field and the hotspots of BIM research. In addition, it laid the knowledge foundation for the future research.

Data used for this paper was originated from the Web of Science Core Collection. There's certain limitations to the research data with the lack of integration with literature from other academic databases (e.g. EI retrieval and Scopus). Future research could consider to integrated with other academic databases.

Author Contributions: L.P. oversaw its development and supervised all aspects of this research. ZW.L. conceived the idea for the paper. YJ.L designed the methodology. All authors have reviewed and approved the final manuscript.

Funding: This research study was supported through sponsorship fund of Building and Construction Authority (BCA) of Singapore. The current study was accomplished as part of a PhD programme.

Acknowledgements: The authors would like to express their gratitude towards Dr Tan Kee Wee, Programme Director, Digitalization Department, Built Environment Research and Innovation Institute (BERII), Building and Construction Authority (BCA) of Singapore.

Conflicts of Interest: The authors declare no conflict of interest.

\section{References}

[1] T. Nath, M. Attarzadeh, R. L. K. Tiong, C. Chidambaram, and Z. Yu, 'Productivity improvement of precast shop drawings generation through BIM-based process re-engineering', Autom. Constr., vol. 54, pp. 54-68, 2015.

[2] S. Azhar, 'Building Information Modeling (BIM): Trends, Benefits, Risks, and Challenges for the AEC Industry', Build. Inf. Model. Trends, Benefits, Risks, Challenges AEC Ind., vol. 11, no. 3, pp. 241-252, 2011. 
926 [3] 'No Title', vol. National B, 2007.

927 [4] Q. He, G. Wang, L. Luo, Q. Shi, J. Xie, and X. Meng, 'Mapping the managerial areas of Building

928 Information Modeling (BIM) using scientometric analysis', Int. J. Proj. Manag., vol. 35, no. 4, pp. 670-685, 2017.

930 [5] Y. Lu, Z. Wu, R. Chang, and Y. Li, ‘Building Information Modeling (BIM) for green buildings: A critical

[6] A. Bradley, H. Li, R. Lark, and S. Dunn, 'BIM for infrastructure: An overall review and constructor perspective', Autom. Constr., vol. 71, pp. 139-152, 2016.

934 [7] M. Hilal, T. Maqsood, and A. Abdekhodaee, 'A scientometric analysis of BIM studies in facilities management', Int. J. Build. Pathol. Adapt., 2018.

Saka and Chan, 'A Scientometric Review and Metasynthesis of Building Information Modelling (BIM) Research in Africa', Buildings, vol. 9, no. 4, p. 85, 2019.

[10] Clarivate Analytics, 'Web of Science Databases', Clarivate, 2019. [Online]. Available: https://clarivate.com/products/web-of-science/databases/. [Accessed: 18-May-2019].

[11] J. Haymaker, J. Kunz, B. Suter, and M. Fischer, ‘Perspectors: Composable, reusable reasoning modules to construct an engineering view from other engineering views', Adv. Eng. Informatics, vol. 18, no. 1, pp. 49-67, 2004.

[12] J. Yang, C. Cheng, S. Shen, and S. Yang, 'Comparison of Complex Network Analysis Software : Citespace

[13] C. Chen, 'CiteSpace'. [Online]. Available: http://cluster.cis.drexel.edu/ cchen/citespace/. [Accessed: 04Apr-2019].

949 [14] C. for N. S. Center, 'Sci2 Tool - A Tool for Science Research \& Practice', 2010. [Online]. Available: https://sci2.cns.iu.edu/user/developer.php?PHPSESSID=au1qkcr942al6ea071s06g5pd2.

[15] O. Persson, 'BibExcel'. [Online]. Available: https://homepage.univie.ac.at/juan.gorraiz/bibexcel/. [Accessed: 04-Apr-2019].

[16] M. J. Cobo, A. G. López-Herrera, E. Herrera-Viedma, and F. Herrera, 'Science mapping software tools: Review, analysis, and cooperative study among tools', J. Am. Soc. Inf. Sci. Technol., vol. 62, no. 7, pp. 1382-1402, 2011.

C. Chen, 'Science Mapping Tools', 2017. [Online]. Available: http://cluster.cis.drexel.edu/ cchen/citespace/resources/. [Accessed: 18-May-2019]. networks', Proc. - IEEE Symp. Inf. Vis. INFO VIS, pp. 67-74, 2003. 
November 2004, pp. 85-110, 2005.

963

964

965

966

967

968

969

970

971

972

973

974

975

976

977

978

979

980

981

982

983

984

985

986

987

988

989

990

991

992

993

994

995

996

[20] X. Zhao, 'A scientometric review of global BIM research: Analysis and visualization', Autom. Constr., vol. 80, no. April, pp. 37-47, 2017.

[21] N. Measure, 'Co-citation in the Scientific Literature: A New Measure of the Relationship Between Two Documents', J. Am. Soc. Inf. Sci., vol. 24, no. 4, pp. 265-269, 1973.

[22] C. T. S. L. Eastman, BIM Handbook:A Guide to Building Information Modeling for Owners, Managers, Designers, Engineers, and Contractors. 2008.

[23] M. Venugopal, C. M. Eastman, R. Sacks, and J. Teizer, 'Semantics of model views for information exchanges using the industry foundation class schema', Adv. Eng. Informatics, vol. 26, no. 2, pp. 411-428, 2012.

[24] B. Succar, 'Building information modelling framework: A research and delivery foundation for industry stakeholders', Autom. Constr., vol. 18, no. 3, pp. 357-375, 2009.

[25] R. Volk, J. Stengel, and F. Schultmann, 'Building Information Modeling (BIM) for existing buildings Literature review and future needs', Autom. Constr., vol. 38, pp. 109-127, 2014.

[26] L. Koskela, C. Usher, M. Kagioglou, K. O’Reilly, P. Coates, and Y. Arayici, 'Technology adoption in the BIM implementation for lean architectural practice', Autom. Constr., vol. 20, no. 2, pp. 189-195, 2010.

[27] T. Hartmann, J. Gao, and M. Fischer, 'Areas of Application for 3D and 4D Models on Construction Projects', J. Constr. Eng. Manag., vol. 134, no. 10, pp. 776-785, 2008.

[28] S. Azhar, W. A. Carlton, D. Olsen, and I. Ahmad, 'Building information modeling for sustainable design and LEED $®$ rating analysis', Autom. Constr., vol. 20, no. 2, pp. 217-224, 2011.

[29] T. Hartmann, H. Van Meerveld, N. Vossebeld, and A. Adriaanse, 'Aligning building information model tools and construction management methods', Autom. Constr., vol. 22, pp. 605-613, 2012.

[30] R. Howard and B. C. Björk, 'Building information modelling - Experts' views on standardisation and industry deployment', Adv. Eng. Informatics, vol. 22, no. 2, pp. 271-280, 2008.

[31] R. Sacks, C. M. Eastman, and G. Lee, 'Parametric 3D modeling in building construction with examples from precast concrete', Autom. Constr., vol. 13, no. 3, pp. 291-312, 2004.

[32] R. Sacks and R. Barak, 'Teaching BIM as an integral part of freshman year civil engineering education', J. Prof. Issues Eng. Educ. Pract., vol. 136, no. 1, pp. 30-38, 2010.

[33] Q. He and G. Wang, 'Hotspots Evolution and Frontier Analysis of Lean Construction Research\&mdash;Integrated Scientometric Analysis using the Web of Science and Scopus Databases', Front. Eng. Manag., vol. 2, no. 2, p. 141, 2016.

[34] C. Chen, 'Collaborative interdisciplinary astrobiology research: A bibliometric study of the nasa astrobiology institute', Scientometrics, 2015. .

[35] C. Eastman, J. min Lee, Y. suk Jeong, and J. kook Lee, 'Automatic rule-based checking of building designs', Autom. Constr., vol. 18, no. 8, pp. 1011-1033, 2009. 
[36] J. Irizarry, E. P. Karan, and F. Jalaei, 'Integrating BIM and GIS to improve the visual monitoring of construction supply chain management', Autom. Constr., vol. 31, pp. 241-254, 2013.

[37] U. Isikdag, J. Underwood, and G. Aouad, 'An investigation into the applicability of building information models in geospatial environment in support of site selection and fire response management processes', Adv. Eng. Informatics, vol. 22, no. 4, pp. 504-519, 2008.

[38] J. D. Goedert, D. Ph, M. Asce, and P. Meadati, 'Holder - Building Information Modeling', no. July, pp. 509-516, 2008.

[39] by K. Dana Smith, M. Tardif, A. Aia, and C. John Wiley, 'Building Information Modeling: A Strategic Implementation Guide', 2009.

[40] C. S. Dossick and G. Neff, 'Organizational Divisions in BIM-Enabled Commercial Construction', J. Constr. Eng. Manag., vol. 136, no. 4, pp. 459-467, 2009.

[41] R. Sacks, L. Koskela, B. A. Dave, and R. Owen, 'Sacks2010.Pdf', J. Constr. Eng. Manag., vol. 136, no. 9, pp. 968-980, 2010.

[42] D. Bryde, M. Broquetas, and J. M. Volm, 'The project benefits of building information modelling (BIM)', Int. J. Proj. Manag., vol. 31, no. 7, pp. 971-980, 2013.

[43] N. Gu and K. London, 'Understanding and facilitating BIM adoption in the AEC industry', Autom. Constr., vol. 19, no. 8, pp. 988-999, 2010.

[44] S. Azhar, .'D., a.M.Asce', Build. Inf. Model. Trends, Benefits, Risks, Challenges AEC Ind., vol. 11, no. 3, pp. 241-252, 2011.

[45] Y. Jung and M. Joo, 'Building information modelling (BIM) framework for practical implementation', Autom. Constr., vol. 20, no. 2, pp. 126-133, 2011.

[46] B. Akinci, P. Tang, R. Lipman, A. Lytle, and D. Huber, 'Automatic reconstruction of as-built building information models from laser-scanned point clouds: A review of related techniques', Autom. Constr., vol. 19, no. 7, pp. 829-843, 2010.

[47] K. L. Chuck Eastman, Paul Teicholz, Rafael Sacks, 'BIM Handbook: A guide to Building Information Modeling for owners, managers, designers, engineers and contractors', Constr. Econ. Build., vol. 12, no. 3, pp. 101-102, 2014.

[48] V. Singh, N. Gu, and X. Wang, 'A theoretical framework of a BIM-based multi-disciplinary collaboration platform', Autom. Constr., vol. 20, no. 2, pp. 134-144, 2011.

[49] T. Cerovsek, 'A review and outlook for a "Building Information Model” (BIM): A multi-standpoint framework for technological development', Adv. Eng. Informatics, vol. 25, no. 2, pp. 224-244, 2011.

[50] S. Azhar, W. A. Carlton, D. Olsen, and I. Ahmad, 'Building information modeling for sustainable design and LEED $®$ rating analysis', Autom. Constr., vol. 20, no. 2, pp. 217-224, 2011.

A. Schlueter and F. Thesseling, 'Building information model based energy/exergy performance assessment in early design stages', Autom. Constr., vol. 18, no. 2, pp. 153-163, 2009.

[52] B. Becerik-Gerber and S. Rice, 'The perceived value of building information modeling in the U.S. 

building industry', Electron. J. Inf. Technol. Constr., vol. 15, no. February, pp. 185-201, 2010.

1034

1035

1036

1037

1038

1039

1040

1041

1042

1043

1044

1045

1046

1047

1048

1049

1050

1051

1052

1053

1054

1055

1056

1057

1058

1059

1060

1061

1062

$[66]$

[53] A. Redmond, A. Hore, M. Alshawi, and R. West, 'Exploring how information exchanges can be enhanced through Cloud BIM', Autom. Constr., vol. 24, pp. 175-183, 2012.

[54] L. Ding, Y. Zhou, and B. Akinci, 'Building Information Modeling (BIM) application framework: The process of expanding from 3D to computable nD', Autom. Constr., vol. 46, pp. 82-93, 2014.

[55] J. K. W. Wong and J. Zhou, ‘Enhancing environmental sustainability over building life cycles through green BIM: A review', Autom. Constr., vol. 57, pp. 156-165, 2015.

[56] R. Sacks, I. Kaner, C. M. Eastman, and Y. S. Jeong, 'The Rosewood experiment - Building information modeling and interoperability for architectural precast facades', Autom. Constr., vol. 19, no. 4, pp. 419$432,2010$.

[57] Cabinet Office, 'Government Construction Strategy', Construction, no. July, p. 5, 2011.

[58] G. Aranda-Mena, J. Crawford, A. Chevez, and T. Froese, ‘Building information modelling demystified: does it make business sense to adopt BIM?', Int. J. Manag. Proj. Bus., vol. 2, no. 3, pp. 419-434, 2009.

[59] J. Steel, R. Drogemuller, and B. Toth, 'Model interoperability in building information modelling', Softw. Syst. Model., vol. 11, no. 1, pp. 99-109, 2012.

[60] R. Sebastian, 'Changing roles of the clients, architects and contractors through BIM', Eng. Constr. Archit. Manag., vol. 18, no. 2, pp. 176-187, 2011.

[61] M. Yalcinkaya and V. Singh, 'Patterns and trends in Building Information Modeling (BIM) research: A Latent Semantic Analysis', Autom. Constr., vol. 59, pp. 68-80, 2015.

[62] H. Y. Chong, C. Y. Lee, and X. Wang, 'A mixed review of the adoption of Building Information Modelling (BIM) for sustainability', J. Clean. Prod., vol. 142, pp. 4114-4126, 2017.

[63] B. Becerik-Gerber, F. Jazizadeh, N. Li, and G. Calis, 'Application Areas and Data Requirements for BIMEnabled Facilities Management', J. Constr. Eng. Manag., vol. 138, no. 3, pp. 431-442, 2011.

[64] D. Cao, G. Wang, H. Li, M. Skitmore, T. Huang, and W. Zhang, 'Practices and effectiveness of building information modelling in construction projects in China', Autom. Constr., vol. 49, no. PA, pp. 113-122, 2015.

[65] I. Motawa and A. Almarshad, 'A knowledge-based BIM system for building maintenance', Autom. Constr., vol. 29, pp. 173-182, 2013.

1063 